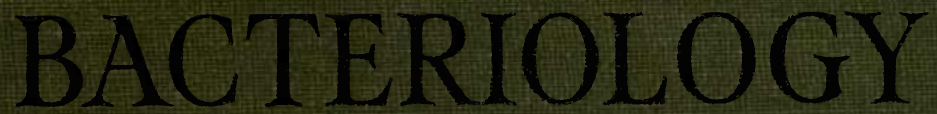

W.E.CARNEGIE DICKSON,M.D.

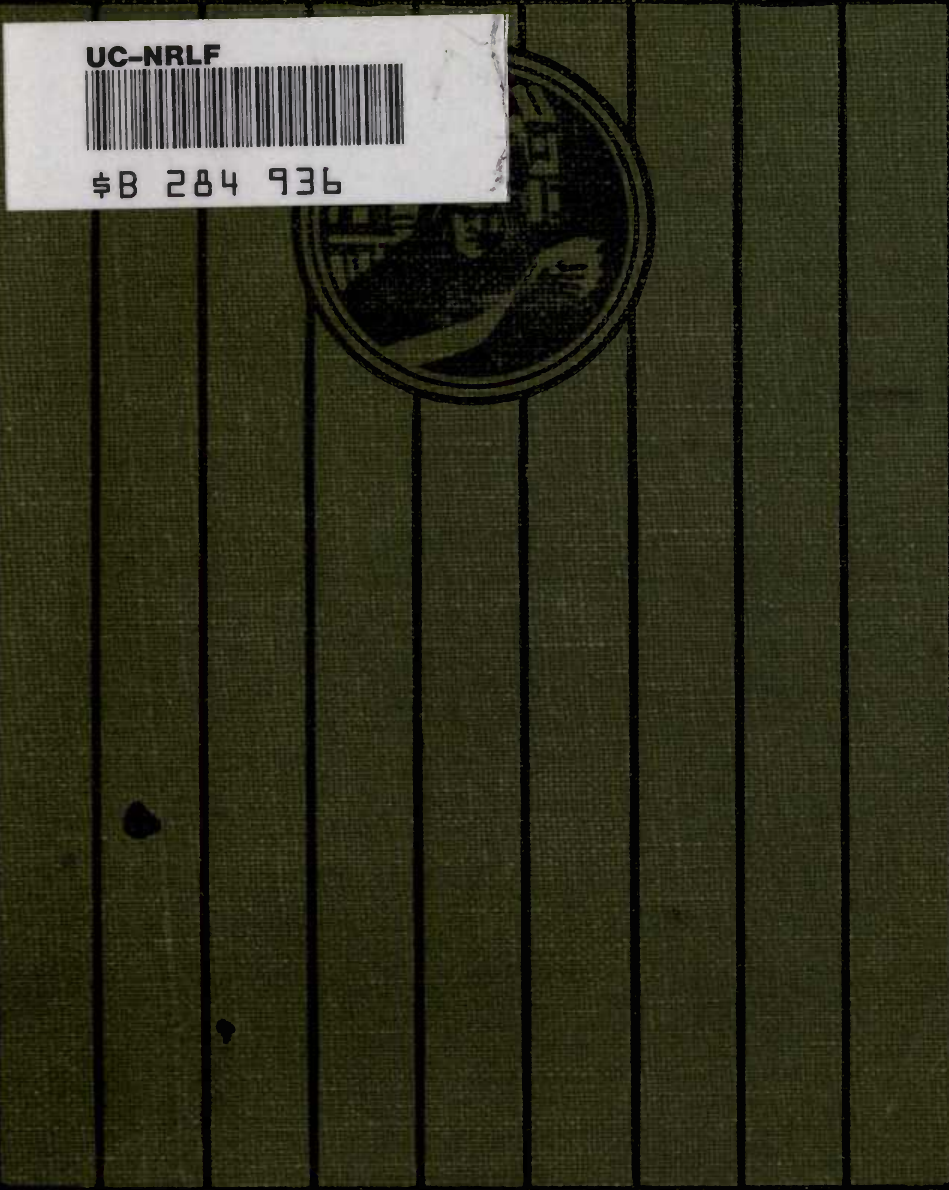





\section{BACTERIOLOGY MAN'S MICROBE FRIENDS AND FOES}

By W. E. CARNEGIE DICKSON M.D., B.Sc., F.R.C.P. EnIN.

LEOTURER ON APPLTED BAOTERIOLOGY IN THT UNIVERSITY OF EDINBURGH

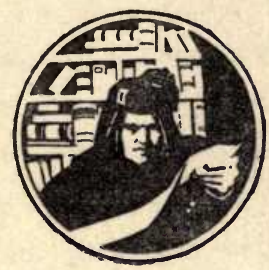

L O N D N : T. C. \& E. C. J A C K 67 LONG ACRE, W.C., AND EDINBURGH NEW YORK: DODGE PUBLISHING CO. 


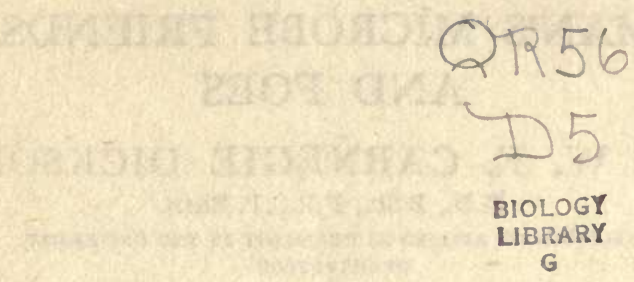

$$
\begin{aligned}
& \because \because \vdots \quad, \because \vdots \vdots \vdots \vdots \\
& \therefore \because \vdots \because \because \vdots \vdots \cdots \cdots
\end{aligned}
$$




\section{CONTENTS}

CHAP.

PAGE

I. INTRODUCTORY • • • • • • • • 9

II. Historical $\quad . \quad$.

III. The Scope and Departments of Bacteriology • 21

IV. Methods of Studying Bacteria; aNd their Morphology AND Life History. • • . 23

V. Health and Disease • • • • • • 42

VI. Modes of the Entrance of Pathogenic BacTERIA INTO THE Body, AND their ACTion. • 48

VII. SOME OF the COMmoner ORganisms WHICH PRO-

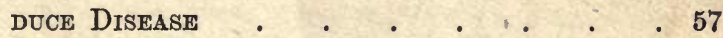

VIII. Bacteria and Plants-Bacteria in the Arts AND INdustries-Commercial BaCteriology • 89 Bibliography . . • • • • • . 96 



\section{$\therefore 0$}

BACTERIOLOGY

\section{CHAPTER I}

\section{INTRODUCTORY}

Bacteriology-or Micro-biology as it might more conveniently and correctly be entitled-the scientific study of bacteria and their relatives-or of microbes-is essentially a new and rapidly advancing science, and has been developed practically within the lifetime of the present generation. This rapid and recent growth is in large part due to a correspondingly rapid development in certain of the arts and sciences, notably in the science of optics and the art of lens-making, which have given us the modern compound microscope; whilst chemistry has brought to our aid, amongst other things, its coal-tar products, the aniline dyes, by the use of which the microbes may be stained and rendered more easily visible when looked at through the microscope. To these, and also to the experimental methods of bacteriology itself, especially the cultivation or the growing of bacteria upon artificial media, the inoculation of animals, and similar procedures, most of the wonderful and far-reaching discoveries in medical, commercial, agricultural and other departments of bacteriology have been due.

Before going farther, we must have some rough idea of what we mean when we speak of "bacteria," "germs," "microbes," "micro-organisms," and the like. Considerable confusion exists in the use of these terms, and, indeed, they are often used indiscriminately and as synonymous with one another.

Although, strictly speaking, Bacteriology, the term generally used in this connection, should mean the science which deals with bacteria, and with these alone, yet, by common consent, not only many other closely-allied micro-organisms, but also many which differ from them widely in nature, are now studied and included along with them under the general term Bacteriology.

The word Bacterium, derived from the Greek bakterion (a diminutive of the Greek word baktron, a staff or stick), was at first applied by microscopists to certain small rod-shaped organisms belonging to the lowest rank of vegetable life. It is now used indiscriminately for the whole group of such 
organiams, regardless of their shape alone, the term Bacillus boing réservod for those which resemble a rod in shape.

Between thirty and forty years ago, when scientists were first turning their attention to this field of research, a somewhat heated controversy arose between botanists and zoologists as to whether bacteria belonged to the vegetable or to the animal kingdom, a dispute which is now considered to be settled in favour of the claims of the former. But before this settlement was arrived at, a sort of truce was patched up between the contending parties at the instance of certain French scientists, Sédillot, in 1878, suggesting that the torm Microbe (from the Greek mikros, small, and bios, life), might be used without definitely giving the decision in favour of either party. At the present day this word microbe is still a useful term for describing microscopic organisms both vegetable and animal, or where doubt yet exists as to which great group should contain them.

A similar use is made of the somewhat popular term Germ (from the French germe, and Latin germen, a bud), which signifies merely some rudimentary form of living matter, whether plant or animal. Indeed, the dispute is a somewhat profitless one, as the terms "plant" and "animal" were, of course, invented long before these simpler, and practically intermediate, forms of life were discovered. It is an easy matter to distinguish, say, a cat from a cabbage, or a butterfly from a flower ; but, as we pass lower and lower down the scale, it becomes more and more difficult, and in truth, at the very bottom, no hard and fast line of demarcation can be drawn between the two categories. Bacteriologists are still in doubt as to whether some of the organisms with which they deal should be classed as animal or vegetable; and their difficulties in classification are now still further increased by the comparatively recent discovery of the existence of certain still smaller living organisms-the so-called ultra-microscopic filter-passers, for which the name "Chlamydozoa" has been suggested-which are so minute that they are scarcely visible or even quite invisible with the highest powers of the microscope at present available, but which can be proved by experimental methods to be the cause of certain diseases such as smallpox, yellow fever, infantile paralysis, foot-and-mouth disease, and other acute infective fevers, including in all probability measles and scarlet fever, as well as swine fever, pleuro-pneumonia in cattle, fowlplague, and other diseases of the lower animals. The exact nature of these filter-passers is not yet established, and it is as yet too soon to speculate as to whether they are bacterial or protozoal, or belong to an entirely new and distinct class 
by themselves. Some of them have now been successfully cultivated outside the body, notably the microbe of pleuropneumonia by Nocard and Roux, and of infantile paralysis by Flexner and Noguchi of New York.

At the lowest part of the ladder of life, then, there are numerous very simple forms, the animal gradually merging with the vegetable, and to this group of simplest forms the German naturalist, Haeckel, has proposed that the term Protista or Protists should be given. Under this term he includes primitive plants (Protophyta) and primitive animals (Protozoa), both of which will have to be briefly studied under our sub-title of "Man's Microbe Friends and Foes."

We may now therefore, conveniently review in tabular form the scientific classification of vegetable and animal life, in order to realise the position of these microbe plants and animals, for the fuller consideration of which reference may be made to special works on Botany and Zoology.

It may be said that these classifications are of interest only to specialists and scientists, but they are included here merely to indicate the orderly arrangement that is necessary in the minuter study of such subjects, and to demonstrate the position of the group of organisms, whether we call them microbes, germs, bacteria, or designate them by other names.

It is to the lowest group in each series, the Thallophytes and the Protozoa, that our attention will be more particularly directed, and therefore the subdivisions of these special groups are given somewhat more fully.

\section{CHIEF DIVISIONS OF THE VEGETABLE KINGDOM}

A. Phanerogams or Spermatophyta : these are the true flowering plants, and contain the two great groups:

I. The Angiosperms : foliacious trees, shrubs, herbaceous plants, and grasses.

II. The Gymnosperms : coniferous or cone-bearing trees (pines, firs, \&c.), and their relatives, the cycads.

B. Cryptogams or non-flowering plants:

I. Pteridophyta : the ferns, horse-tails, club-mosses, \&c.

II. Bryophyta : the mosses and liverworts.

III. Thallophyta: algae, seaweeds, fungi, moulds, bacteria, etc. These are all comparatively simple in structure.

\section{Classification of the Thallophyta}

This large group is characterised by the absence of any differentiation into root, stem, leaves, etc. Its members are therefore very primitive in structure, and include among their 
number the majority of the organisms studied in Bacteriology. It is subdivided as follows :

1. Euphyceae or true Algae: these vary from the simple, thread-like and microscopic forms found in ponds and stagnant pools and in moist places, up to the more, and sometimes highly, complex, forms such as the seaweeds, some of which may be several hundred feet long. They are all characterised by the presence of chlorophyll, the green substance by which plants, under the influence of sunlight, can absorb their food and build it up into more complex substances, and are thus differentiated from the fungi, which some authorities regard as modified algae which have lost their chlorophyll. The resemblance of some of these to bacteria is merely superficial. Though none of this group are known to cause definite disease in man, their growth in reservoirs and cisterns may cause deterioration of watersupplies, and they may even sometimes be seen as a green sediment in water-vessels that are not properly cleaned out.

2. Eumycetes or True Fungi : such as toadstools and mushrooms, mildews, moulds, etc. These consist of threadlike structures (hyphae) often forming a network or tangled mass which is known as the mycelium. From these, under suitable conditions, are developed fruit-bearing structures or fructifications, some of which are familiar to us as toadstools or as the velvet-like pile of the moulds - the mycelial threads or fungus proper being underground, or in the substance of the material (cheese, jam, etc.) on which the organism is growing and from which it derives its nourishment.

3. Saccharomycetes or Yeasts: a group coming intermediate between the moulds and the bacteria, are important both in relation to various fermentation-processes and, in less degree, as producers of disease.

4. Diatomaceae : closely allied to the Algae, but possessing a flinty skeleton, sometimes of great beauty. They are found in water and moist places; and fossil deposits of their skeletons constitute the so-called "infusorial earth" used in the manufacture of dynamite and certain kinds of paint. They are not known to produce disease, but are of great interest to the geologist, vast deposits of them being often found in oceanbeds and in rock and other strata originally formed at the bottom of the ocean.

5. Myxomycetes or Slime-Moulds : some writers have classed these in the animal kingdom. They grow upon moist decaying organic matter, and their methods of reproduction are more complex than those of bacteria. They are not of special importance from our present point of view.

6. Myxobacteriaceae: also found growing on moist decay- 
ing organic material, and forming a group intermediate between the slime-moulds and the bacteria proper, and sometimes classed among the latter. They are motile, rod-like organisms, and multiply by simple division or fission.

7. Schizophyta ("fission-plants" or "splitting plants"). This group is, perhaps, the most important from our present point of view, as it includes the Schizomycetes (fission-fungi or splitting fungi), Bacteriaceae or Bacteria, and also their close relatives the Schizophyceae or splitting algae, and the Cyanophyceae, or blue-green fission-algae. The latter occupy a somewhat higher position than bacteria in the scale, as they possess the colouring matter, chlorophyll, along with other pigmentary substances, and are therefore able to assimilate carbon and build up its compounds under the action of sunlight, whilst the bacteria do not possess chlorophyll, and depend upon the breaking up of already formed organic matter, i.e. complex animal or vegetable substances containing the carbon and other elements necessary for their life. The nature of the cell-wall also differs in these two groups or orders, being composed of the carbohydrate or starch-like substance, cellulose, the most abundant solid constituent of vegetable tissues, in the case of the blue-green algae ${ }^{1}$; whilst in bacteria, it is rather to be regarded as a condensation of the protoplasm or body-substance itself. At the lower end of the fission-algae group, however, and at the top of the fission-fungi or bacteria, there are members of each group which have many characteristics in common, which practically unite them into one continuous series.

\section{CHIEF DIVISIONS OF THE ANIMAL KINGDOM}

A. Vertebrata or back-boned animals : mammals, birds, reptiles, amphibia, fishes, \&c.

B. Invertebrata (with no back-bone):

I. Molluses or shell-fish.

II. Arthropods : crustaceans, insects, spiders, \&c.

III. Echinoderms : star-fish, sea-urchins, \&c.

IV. Vermes : worms, segmented and non-segmented.

V. Coelenterates : corals, sea-anemones, jelly-fish, \&c.

VI. Porifera or sponges.

VII. Protozoa, or primitive animals.

\section{Classification of the Protozoa}

1. Rhizopoda, Gymnomyxa, or Sarcodina: mostly naked amoeboid forms, locomotion being effected by the projection of

1 This substance, cellulose, is the chief constituent of such vegetable products as linen, cotton wool, paper, etc. 
"pseudopodia." (In this group is to be found the organism (Entamoeba histolytica) which causes Tropical or Amoebic Dysentery in man.

2. Flagellata or Mastigophora: possessing one or two, rarely a larger number of vibratile hair-like organs. (Members of this class include the parasites of Sleeping Sickness in man, and also certain very serious diseases of cattle, horses, and other animals.)

3. Ciliata : possessing numerous short, vibratile, hair-like "cilia" for locomotion and for waving food-particles into the mouth. (The members of this group are not of any great importance from our present point of view.)

4. Suctoria or Acinetaria : none of these is known to produce disease in man.

5. Sporozoa : members of this class are all parasitic. They feed by absorption, and, except during certain developmental stages, do not possess specialised organs for locomotion. (Malaria, one of the most widespread and serious diseases affecting mankind, is produced by certain closely allied members of this group, whilst others infest and produce important diseases in many of the lower animals.)

From a study of the above facts we are now in a position to realise in some degree what we mean by the terms bacteria, microbe, and the like. We see that, as we pass down the animal and vegetable series, the two main lines approach each other like the limbs of a gigantic letter V, and very near-practically at-the point of junction come the "Protozoa" or primitive animals and the "Protophyta," as we may correspondingly name the primitive plants.

Many of the bacteria resemble animals in being capable of active movement, but it is, of course, common knowledge that this is no real test, for many true animals, sea-anemones, sponges, and the like, are stationary ; whilst some plants and vegetable cells can actively move from place to place. The more important tests are physiological, i.e. connected with the vital activities such as food-absorption, excretion of waste products, and so on, and, though of great scientific interest, scarcely come within the scope of the present volume.

\section{The Classification of the Fission-Fungi (Schizomycetes) or Bacteria into Families}

As this is a matter of great difficulty and complexity, only a short outline need be here attempted. Indeed it is no exaggeration to say that one finds a different classification given in almost every book dealing with bacteriology. This is mainly 
due to the fact that bacteriology as a science has been studied and developed mainly by medical men who have been concerned with the practical bearings of their discoveries, rather than with the scientific classification, a side of the subject which really requires the expert knowledge of the highly-trained botanical and zoological specialist. Until our knowledge of bacteria is much more accurate and intimate, all such classifications must be looked upon as merely provisional. At present we have to depend chiefly upon the shape, size, and method of reproduction of these organisms; but it is probable that physiological and functional activities will, in the future, have to be taken more into account. The classification here given is founded mainly upon that of Migula, which is now generally adopted.

Bacteria are very minute, single-celled, usually colourless and chlorophyll-free, clear, refractile micro-organisms of various shapes and sizes (see Frontispiece). Some are spherical or nearly so, and are termed Cocci, from the Greek word kokkos, signifying a berry. Others are rod-shaped and are therefore called Bacilli or little rods, from the Low Latin word bacillus, the diminutive of baculus, a rod or staff. Some of these are straight or very slightly curved; but when the curve is more distinctly marked they are known as Comma-bacilli or Vibrios. Where these latter are built up into spiral or wavy chains, the name Spirillum is used, though it is often also applied to the single curved unit ; whilst the non-septate spiral rods which are not built of shorter curved elements are called Spirochaetes.

A difficulty here meets us from the fact that certain protozoa of the flagellate group (see p. 14) are in some phases of their life-history practically indistinguishable from these spirochaetes, for example the very important disease-producing Treponema pallidum (see p. 86), which, though probably a protozoon, is often somewhat loosely referred to as a "Spirochaete."

The bacteria above considered belong to the Lower group of Bacteria, sometimes spoken of as the Haplo-bacteria, and to these a large number of disease-producing bacteria belong. Just above them in the scale come bacteria which tend to grow in threads and which are therefore called the Trichomycetes or Tricho-bacteria. They usually possess a common enclosing sheath. Some are unbranched (e.g. Leptothrix group); others show branching (e.g. Streptothrix group), and often exhibit the setting aside of special portions of the threads for reproductive purposes, in this respect approximating in some instances to the moulds in character. The classification of the members of this higher group is extremely 
confusing, as scarcely any two authorities agree on the subject, and further knowledge is required before a satisfactory grouping can be made.

\section{CHAPTER II}

\section{HISTORICAL}

As far as the sciences of Medicine and Public Health are concerned, we have during the past thirty years, as we have already noted, been passing through what may be called the microbiological or bacteriological era, during which for the first time the actual, direct, or exciting causes-as apart from those which prepare the soil for, or predispose towards their occurrence - of the majority of the diseases to which the flesh is heir, have been, or are in process of being discovered. Apart from such obvious causes as tho action of known poisons, physical accidents, cuts, bruises, broken bones, burns, etc., the causation of many diseases is still enwrapped in mystery. The terrible cancer problem still awaits solution. Curious freaks in development are as yet unexplained. The causes of certain errors in metabolism or the chemical processes of the body and many of its important organs, for example the digestive and the ductless glands, are in many cases still unknown. But during the lifetime of the present generation, the actual causal organisms, bacterial, protozoal or otherwise, of a great number of infective diseases have been discovered and studied. Amongst the more important of these diseases may be mentioned tuberculosis in all its protean forms, typhoid fever, diphtheria, leprosy, cholera, plague, influenza, pneumonia, a great variety of inflammatory conditions in different parts of the body, dysentery, malaria, syphilis, sleeping sickness, and many others. Whooping-cough and rhoumatic fover may also be added to this list; whilst it is probably now merely a matter of time for the still unknown viruses of small-pox and vaccination, measles, scarlet fever, chicken-pox, typhus fever, etc., to be isolated and identified, if, indeed, some of these are not already discovered and now merely require definite confirmation.

Perhaps the first historical foreshadowings of the importance of minute living creatures as a cause of disease are to be found in the writings of Athanasius Kircher, the learned Jesuit, mathematician, alchemist, and Oriental scholar, who, two and half centuries ago, among his other profound studies, included the then infant science of optics. With the comparatively simple magnifying lenses at his disposal, he observed the presence of "minute living worms" in putrid meat, vinegar, 
milk and cheose, and suggested that putrefaction and disease were due to minute micro-organisms-a contagium animatum or living cause by which disease was produced and transmitted. His discoveries, however, were received with scepticism, much ais were at first those of Pasteur, the modern father of bacteriology.

In 1683, Anthony van Leeuwenhoek, a learned linen-weaver of Delft, in Holland, wrote a series of interesting letters to the Royal Society of London, describing observations of bacteria and other minute living organisms, which he made through a microscope of his own manufacture, the grinding and polishing of lenses, which he had learned in his youth, being one of his hobbies in later life. In one of these letters he says: "I saw with great astonishment, especially in the material mentioned (the emulsion of tartar from the teeth) that there were many tiny animals which moved about in a most amusing manner; the largest of these showed the liveliest and most active motion, moving through the water or saliva as a fish of prey darts through the sea ; they were found everywhere, although not in large numbers."

Leeuwenhoek was content merely to record his interesting discoveries, and did not attempt to found any theories of the causation of disease, putrefaction, and decay upon them; but other writers who followed him did so, notably the great naturalist Iinnæus, and later a learned Viennese physician, Marcus Antonius Plenciz, who, in 1762, propounded a germ theory as the cause of these processes, believing that each infective disease was caused by its own specific germ, and that decomposition of organic substances was similarly brought about. A farther advance, especially in the classification of these minute organisms, was made in 1786, by the Danish biologist, Otto Friedrich Müller, who introduced many of the terms still in use at the present day, e.g. Vibrio, Bacillus, Spirillum, Proteus, and the like. Other workers, notably Ehrenberg in 1836, and Cohn in 1875, continued the work of discovery and classification; but it is to the extraordinary industry and genius of Louis Pasteur, one of the greatest scientists of the nineteenth century, that modern bacteriology practically owes its existence.

Pasteur was born in 1822 at Dôle in France, and those who are interested in the advance of science would be well repaid by reading the life story of this great man. ${ }^{1}$ It is a record of enormous difficulties and discouragements, and bitter opposition on the part of his so-called scientific opponents, overcome by patient and unremitting industry, lit up by the insight of

1 Louis Pasteur: His Life and Labours. By his son-in-law. Paris, 1883. Translated by Lady Claud Hamilton. London, 1885. 
genius and an infinite capacity for taking pains, and fired too by a love of his country and a desire to holp humanity. His researches into the nature of fermentation, and into the then much vexed question of the spontaneous generation of life, produced results of world-wide importance. He proved conclusively that fermentation was due to organised and living ferments, and that a special ferment (i.e. mioro-organism producing fermentation) corresponded with each variety of the process. He at the same time proved by elaborate and carefully controlled experiments, to his own satisfaction and to that of the vast majority of modern scientists, that "spontaneous generation of life" or abiogenesis, as it was called in learned phrase, was a myth; and that organic material, e.g. fluid infusions of meat or the like, do not decompose, if they are carefully guarded from the presence of contaminating micro-organisms, a subject to which reference will again be made in our Chapter on Sterilisation. Hurtful or noxious and abnormal fermentation-sometimes known as the "diseases"of wines, vinegar, beer, etc., can similarly be prevented by certain simple precautions, such as heating to a suitable temperature and taking the precaution of allowing only the proper organism to act in each case. In 1865, Pasteur also proved that the devastating disease known as Pébrine by which silkworms were attacked, and which had nearly brought ruin upon one of France's chief industries, was due to a protozoal parasite (Nosema bombyces); and he was able, after studying its life-history, to suggest a very simple but yet very efficacious procedure by which its ravages might be prevented.

The treatment of various diseases by "vaccines" next occupied his attention. In 1877, widespread epidemics of Anthrax had been carrying off enormous numbers of sheep and cattle in France, whilst in Russia some 56,000 head of cattle were destroyed in two years. Pasteur succeeded in artificially growing the bacillus which causes the disease, making use of a broth medium for the purpose. He then proceeded to Chartres, around which the epidemic had produced a loss said to have amounted to little short of a million pounds, and studied the disease on the spot. He found that if he inoculated cultures of the bacillus grown artificially at blood temperature $\left(98.6^{\circ} \mathrm{F}\right.$. or $37^{\circ}$ C.) into sheep, they all died ; but that, if he grew the virus at a somewhat higher temperature, viz. $108^{\circ} \mathrm{F}$. (or $42^{\circ} \mathrm{C}$.) at which the organism could still grow, but could not form spores, and kept it for about a fortnight before using it for inoculation, a mild or benign form of the disease was produced, from which the sheep recovered, and were then found to be immune to the ordinary fatal form of anthrax. 
It is curious and perhaps not a little humiliating to-day, when the truth of Pasteur's discoveries is known even by the schoolboy, for us to look back upon the manner in which they were received by those who might have been expected to receive them with acclamation. Many of the medical men and the veterinary surgeons of his day resented the intrusion of a "mere chemist" into their domain, and received his great discoveries, not only with derision, but often with bitter opposition, and he was even accused of concocting his results !

He studied the cause of puerperal infection and the high mortality then following upon child-birth, and found it to be usually due to a chain-like micro-organism called a Streptococcus. He attended a discusision on the subject at the Academy of Medicine in Paris, and listened to the learned doctors of the day putting forward all sorts of hypotheses, each equally wide of the mark. At length he impatiently exclaimed, "None of these things cause the epidemics. It is the nursing and medical staff who carry the microbe from an infected woman to a healthy one!" The learned physician who was speaking said he was afraid this microbe would never be discovered. Pasteur in answer merely went to the blackboard and drew a chain of dots upon it, exclaiming, "There, that is what it is like." Within a few years after this discovery, and owing to the precautions of perfect cleanliness which Pasteur insisted upon, the death-rate from puerperal fever in the Paris Maternity Hospitals fell from 100 or 200 per 1000 to between 1 and 2 per 1000.

Pasteur's life is so fascinating a study, that one is tempted to dwell upon it at a length not permissible in such a small book as this, and we must rest content with merely mentioning his other great achievements in the domain of bacteriology, pathology, and preventive medicine. Chicken Cholera, Hydrophobia or Rabies, one of the most dreadful maladies communicable from animals to man, and other diseases, were investigated and efficacious vaccine treatment of them discovered. Pasteur lived to see his doctrines triumph over all opposition, and he died in 1895, full of honours and years, his name commemorated, not only in his native France, but in many lands, by their "Pasteur Institutes of Preventive Medicine," and by the word "pasteurise," known in practically every household where milk is sterilised for infant food.

His work was carried on and applied especially to surgery by our own great Lister, who wrote to him from Edinburgh, "Allow me to take this opportunity to tender you my most cordial thanks for having, by your brilliant researches, demonstrated to me the truth of the germ theory of putrefaction, and 
which thus furnished me with the principle on which the antiseptic system can be carried out." Again, in 1892, on the occasion of Pasteur's Jubilee celebration, Lister wrote to him : "Truly there does not exist in the entire world any individual to whom the medical sciences owe more than they do to you. Your researches on fermentation have thrown a powerful beam, which has lightened the baleful darkness of surgery, and has transformed the treatment of wounds from a matter of uncertain and too often disastrous empiricism into a scientific art of sure beneficence. Thanks to you, surgery has undergone a complete revolution, which has deprived it of its terrors and has extended almost without limit its efficacious power." John Tyndall, the great English natural philosopher, in speaking of Pasteur's work, said: "We have been scourged by invisible thongs, attacked by impenetrable ambuscades, and it is only to-day that the light of science is being let in upon the murderous dominion of our foes."

The next great advances in bacteriology were due to the discoveries of the German bacteriologist, Robert Koch, who was born in 1843. In 1876, he succeeded in isolating the bacillus of Anthrax in pure culture as it is called, i.e. freed from the presence of all other contaminating organisms. This bacterium had been observed many years previously (1850) by Davaine, in the blood of animals dying from the disease, but it was reserved for Koch to scientifically prove that it and it alone was the cause of the disease. Later, by applying the recent advances made in the development of the microscope and the aniline dyes, but more especially by his discovery of an easy method of separating or isolating bacteria from one another in pure culture by means of his solidified nutrient culture-media, he was able to demonstrate and prove that Tuberculosis (1882) and Cholera (1883) were due to specific bacteria which are now often spoken of by his name-Koch's tubercle bacillus and Koch's comma bacillus of cholera.

From this period onwards, the bacteriological era may be said to come into full swing. Discovery followed upon discovery, and the cause of one disease after another was tracked and studied-a work still going on all over the world in every scientific laboratory and school of medicine. The cause of bacterial diseases such as Typhoid Fever, Diphtheria, Pneumonia, Tetanus, and a host of others ; protozoal diseases such as Malaria, Syphilis, and Sleeping Sickness, have been discovered and the knowledge so gained has been applied to their prevention and cure. Antitoxic and anti-bacterial sera, and vaccines of all descriptions have been added to the doctor's armamentarium for the fighting of disease and death, and it is 
impossible for us now to foresee what more wonderful discoveries in this domain may still lie ahead of us.

Some diseases which have hitherto baffled our attempts to unveil their causes, are now known to be due to living organisms so minute that they cannot even be seen by our present-day microscopes, powerful as these are. Yellow Fever, Infantile Paralysis, Foot-and-Mouth Disease, are among the number of these. But recently the successful cultivation of the organism causing the second of these diseases has just been announced in New York; and it remains to be seen whether advances in the resources of optical and chemical science and experiments on animals will lead to the discovery of the nature of these at present " ultra-microscopic" germs, and how they may be dealt with for our protection.

\section{CHAPTER III}

\section{THE SCOPE AND DEPARTMENTS OF BACTERIOLOGY}

THE field of General Bacteriology is so vast and complex, so ever broadening, that no single individual is now able to deal with it in all its branches, and there has therefore been an inevitable tendency for it to be split up into special great subdivisions or branches; and even these main subdivisions are so extensive that, in all probability, they too will in turn in the future undergo further subdivision among specialists, each with a particular knowledge of his own and a general knowledge of his colleagues' fields of labour.

At present we may recognise the following main subdivisions of bacteriology, each to some extent overlapping the other, but each in itself affording a definite field of research.

Medical Bacteriology may be placed at the head of the list, as it has been the pioneer leading the way in the development of the whole science, and along with it may be included the special fields of Dental and Veterinary Bacteriology. Medical Bacteriology has itself come to be subdivided into two great fields, Pathological Bacteriology, the study of organisms in relation to the methods of causation, the processes, and the treatment of disease in man and animals, on the one hand: and Hygienic, Public Health, or Sanitary Bacteriology, the study of the mode of spread of such organisms, their presence in food and in air, water, soil, sewage, etc., and the prevention of disease by the methods of Public Health, State or Preventive Medicine on the other. The practical application of a knowledge of bacteriology is also required, not only for Sanitary 
Building and Engineering, but for other more general departments of these professions as well. The preservation of building and other materials against decay is one of the most important aspects in this direction, and such preventive measures as the creosoting of railway sleepers, the tarring of wooden sheds and fences, the protection of piers and ships against the attacks of micro-organisms, or of the woodwork of houses against various forms of rot, are a few of the important points which suggest themselves in this direction.

Then there are various extremely important Industrial or Commercial Departments of the science. Agricultural and Horticultural Bacteriology is a rapidly growing specialty, and includes a knowledge of such matters as the relation of microorganisms to the fertility of the soil, to the diseases of plants and of farm animals, to milk and the manufacture of butter, cheese, and other dairy produce, etc., as well as to the preservation of milk and other food from contamination, a direction in which the much-needed legislation of the present day is now fortunately tending, much unnecessary and preventable disease being directly traceable to such sources.

Other important industries also largely depend upon the action of micro-organisms, for example those concerned with the production of alcohol and other substances by fermentation, baking, tanning, flax-retting, and even, it is said, tobaccocuring; whilst in others again, e.g. in meat-canning, jam-making, and the like, an all-important point is the preservation of their products against the presence and attack of putrefactive or other deleterious micro-organisms.

In the management of everyday household affairs, some elementary conception of bacteriology is of immense valuehow hurtful organisms can be destroyed by heat, as in the cooking of food and the "pasteurising " of milk ; how food may be preserved and protected from the action of bacteria; the use of reasonable cleanliness, personal and otherwise, careful attention to the state of the teeth and mouth, and the prevention of the spread of many diseases such as tuberculosis and the acute infective fevers; the prevention of the spread of skin and other diseases in the barber's shop; the use of antiseptics and disinfectants for suitable purposes; and a knowledge of how disease is spread, not only by man himself, but also by animals such as domestic pets, rats, mice, and even by insects. In all of these and in many other instances a reasonable and commonsense application of such knowledge will often help to prevent much trouble, expense, disease, and perhaps even the death of members of the household. 


\section{CHAPTER IV}

\section{METHODS OF STUDYING BACTERIA; AND THEIR MORPHOLOGY AND LIFE-HISTORY}

Perhaps the most important instrument in the bacteriologist's outfit is a good Compound Microscope of sufficient power, i.e. capable of magnifying by about one thousand diameters. For a detailed description of such a microscope, reference should be made to books on optics and to the illustrated catalogues of the instrument makers, and it is sufficient for our present purpose to refer the reader to the accompanying illustration (seo Fig. 1). The usual outfit of microscopical accessories, such as slides, specially thin or "No. 1 " cover-slips, etc., are of course also required.

With regard to the various Stains or Dyes and other reagents employed to differentiate and make micro-organisms more easily visible, it is sufficient here to say that the bacterial protoplasm as a rule stains most readily with the basic aniline dyes. Protozoal parasites are usually demonstrated by rather more complex methods of staining, and for the technical details reference should be made to the specialtext-books enumerated at the end of this volume.

In order to study thoroughly any given organism, it is usually desirable to be able to isolate it from other contaminating microbes, and

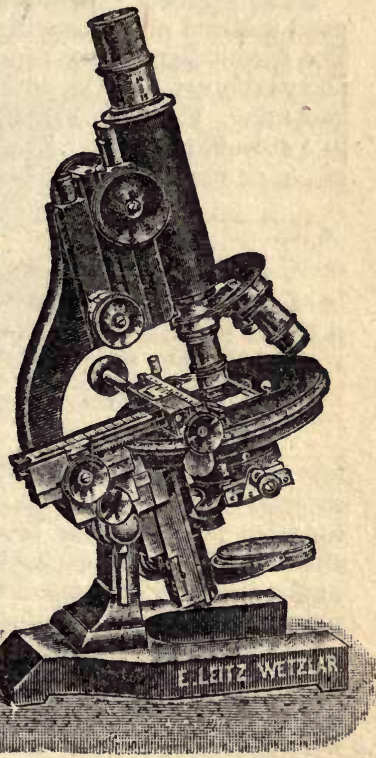

Fra. 1.-Large Model Bacteriological Microscope, fitted with eye-piece, Abbé condenser and iris diaphragm, triple nose-piece, and three objectives.

therefore one of the first problems we have to face is how these contaminating microbes are to be excluded from our apparatus, and this leads us to a consideration of the important subject of Sterilisation, i.e. the means by which we can destroy any organisms already present, and then exclude all others except the special variety we wish to study. We must 
take it for granted that all pieces of apparatus not previously sterilised are already contaminated with organisms from air or water, fingers, or packing material, etc. Spores of moulds and of bacteria, bacteria themselves, yeasts and other living organisms are certain to be present, and mere "ordinary cleanliness" such as washing removes only the excess of theseenormous numbers may be left on objects which to the eye appear polished and clean in the ordinary household sense ; and bacteriological cleanliness has a much more exacting standard.

Heat applied in some way or other, is the most commonly used method of destroying all such contaminating organisms. The direct flame may be employed, as for example in sterilising the platinum needle with which the bacteriologist "handles" bacteria. This (see Fig. 2) is a piece of platinum wire mounted in a suitable handle. The end of the wire is either straight and plain, or has upon it a loop with which the bacteriologist can

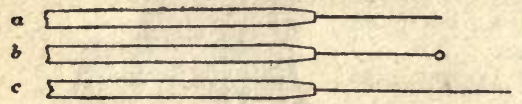

FiG. 2. - Platinum "Needles." a. Ordinary Straight, for making stab-cultures, etc. $b$. Ordinary Looped, for making surface cultures, etc. c. Long Straight, for making deep stab-cultures.

for examination under the microscope. hor cheaper substitute such as stiff electrio resistance wire-is used for this purpose because it stands heating indefinitely, and before and after use it is sterilised by holding it directly in the flame of a Bunsen burner or spirit-lamp. Similarly the points of forceps or any other instrument not spoiled by such a procedure (e.g. hypodermic needles, etc., if made of platinumiridium) can be sterilised in the direct flame; and of course it is common knowledge that infected material such as bodily excretions, old surgical dressings, and the like, are best disposed of by burning.

Many instruments and pieces of apparatus used by the bacteriologist, however, cannot withstand exposure to the direct flame, and dry heat in the form of hot air may be used for such items as test-tubes, flasks, and other glass-ware, copper and certain other metallic objects, etc. Of course tempered steel instruments, rubber goods, etc., cannot be so treated. A temperature of $160^{\circ}$ or $170^{\circ} \mathrm{C}$. is usually employed, and is generally obtained by using a double-walled copper or iron box like a small cupboard (see Fig. 3) which can be heated - most commonly by gas or electricity-but it should be noted 


\section{METHODS OF STUDYING BACTERIA}

that an ordinary kitchen oven may be used, the temperature being gauged by a thermometer or in some other way. An exposure of an hour at this temperature is practically certain to kill off all organised life. Flasks and test-tubes are first plugged with dry cotton-wool, as it has been found by experience that this material acts as a filter for air, but prevents the entrance of organisms into the interior of vessels so plugged.

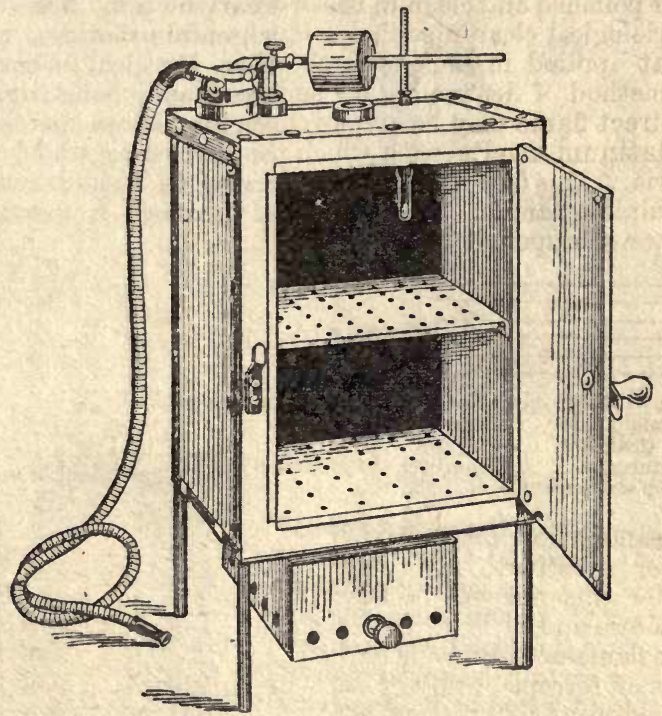

FIa. 3. - Hot Air Steriliser, strongly made in Sheet Iron or Copper, covered with Asbestos to prevent loss of heat. Fitted with Hearson's Patent Automatic Gas Valve and Capsule, capable of maintaining any temperature up to $156^{\circ}$ C. $\left(=250^{\circ} \mathrm{F}\right.$.). Electricity may also be used as a source of heat.

It should be remembered here, however, in passing, that wet cotton-wool does not possess this property, and that moulds, etc., falling upon morst cotton-wool can grow down through it, and so obtain access to the contents of the vessel. The interior of tubes, flasks, bottles, etc., plugged with dry wool and sterilised in this manner, remain free from living organisms for an indefinite period (see Figs. 11 and 12).

Again, moist heat may be employed for objects which will withstand its action. This, as in ordinary domestic cooking, 
may be used either in the form of boiling or of steaming. Various special sterilisers have been designed for use in labora-

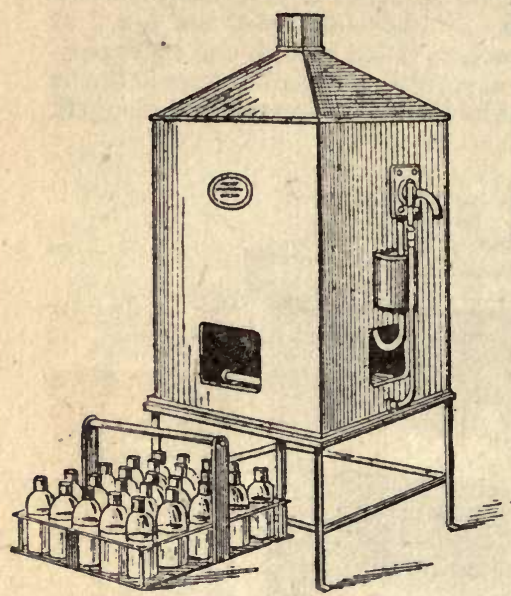
tories, but the amateur bacteriologist, if he does not possess these, can always use any convenient domestic utensil, such as a kitchen pot, fish-kettle, vegetable-steamer, or the like. Surgical instruments are usually boiled up thoroughly before use, a lump of soda being added to the water to hinder corrosion of the steel. In this method

Frr. 4.-Hearson's Milk Steriliser.

of applying heat, the objects sterilised are exposed to a temperature of $100^{\circ} \mathrm{C}$., i.e. the boiling point of water; or if a somewhat higher temperature is desired, e.g. in order to destroy certain bacterial spores which are not killed by boiling even for a considerable time, superheated steam under pressure may be employed, and is obtained by using a specially strongly con. structed pioce of apparatus known as an autoclave, the lid or door of which can be firmly screwed or clamped down so as to tightly close the heating chamber. A special safety valve is fitted to the autoclave, and can be so regulated that the steam "blows off" above a required pressure, the additional temperature above the boiling point being calculated from the pressure indicated on the gauge as in an ordinary steam-boiler. 
Higher temperatures may be obtained by using boiling oils and other fluids, whilst lower temperatures may be got by means of water-baths or special thermostat-ovens with various automatic heat-regulating mechanisms. Vaccines and sera have often to be sterilised at temperatures much below the boiling point, in order not to destroy their potency. Most non-sporing organisms are killed by prolonged heating at or about $60^{\circ} \mathrm{C}$., and this method is often made use of, as in the "pasteurising" of milk and other fluids, in which organisms such as Bacillus coli, Bacillus tuberculosis, etc., may be so weakened or killed by an exposure of, say, twenty minutes at $60^{\circ} \mathrm{C} .\left(=140^{\circ} \mathrm{F}\right.$.) as to be rendered innocuous.

Exposure of infective material to the action of direct sunlight, or in some cases even bright diffuse daylight, may kill off the organisms present, whilst the action of $X$-rays, Finsen light, ultra-violet rays and other forms of radio-activity may also be employed, especially as a therapeutic measure, e.g. in ringworm, lupus (a form of skin tuberculosis), favus, certain forms of eczema, etc. Ultra-violet light is sometimes used for the sterilisation of drinkingwater, and specially devised apparatus for this purpose often forms part of the modern military campaigning equipment. The sterilisation of milk and other fluids by means of the electric current is

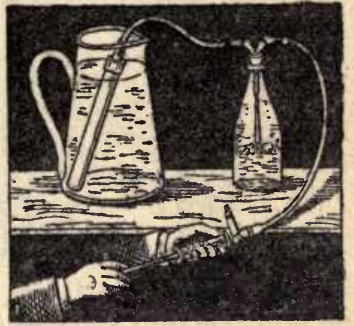

FIG. 6. - Berkefeldt's Filtering Apparatus, complete, with porous cylinder, vacuum flask, india-rubber stopper, and exhaust pump. now being experimentally tested, and will in all probability bo extensively used in the near future.

Many fluids may be rendered sterile by the application of heat at varying temperatures and for varying periods; but where any of their properties are destroyed by such a procedure, they may be passed through a suitable filter (see Figs. 6 and 7), itself previously sterilised, the pores of which are so minute as to prevent the passage of bacteria. A fine grade of unglazed porcelain or some similar material is usually employed for this purpose. Various domestio filters of this description are omployed for rendering drinking-water germ-free (Fig. 6), and fluids such as serum or fluid culture-media may also be so treated. It is common knowledge that filtration through gravel and sand is employed on a large scale for the purification of water-supplies, though such filtration, from a bacteriological point of view, is always incomplete, a certain number of micro- 
organisms passing through and being found even in the best water-supplies, an arbitrary standard of reasonable purity being laid down. It has been found by experience that water, say for a town water-supply, is greatly improved as regards its bacterial content by being stored for a varying period in reservoirs before the filtration is carried out, a large number of bacteria disappearing spontaneously in the process. Similarly ordinary river-water becomes much purer by passage through a lake or reservoir.

Another very important method of destroying bacteria is by the addition of chemical disinfectants. Thus diseased discharges such as tuberculous sputum, typhoid stools, etc., may be rendered noninfective by the addition of

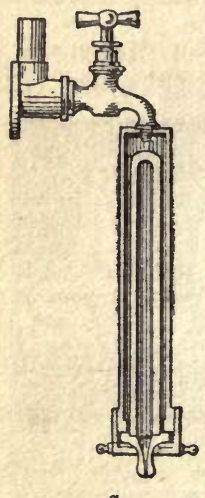

a

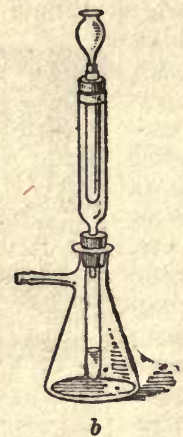

FrG. 7.- $a$. Chamberland's Porous Filter, mounted in metal tube, with tap to fit the water supply for domestic use. b. Filtering apparatus for the filtration of smallquantities of fluid, such as toxins, serum, etc.

dressing of wounds in order to $p$ dressing of wounds in order to prevent the occurrence of sepsis or infection by organisms, and of course most of them also act as disinfectants if organisms are already present. A very important present-day problem is the question of the addition of such substances as boracic acid, salicylic acid, formalin, etc., to articles of food, e.g. milk, jam, etc. The constant taking of some of these into the human body may in some cases be highly deleterious, and, moreover, may give rise to a false security as regards the presence or absence of micro-organisms, as some of them merely inhibit the growth of putrefactive organisms, whilst the disease-producing bacteria may not only not be destroyed, but may actually have a better opportunity 
Bacterial Content of Different Types of Water

\begin{tabular}{|c|c|c|}
\hline Type of Water. & $\begin{array}{l}\text { Average No. of Bac- } \\
\text { teria per c.c. }\end{array}$ & $\begin{array}{l}\text { Chief Factors influencing } \\
\text { Bacterial Content. }\end{array}$ \\
\hline $\begin{array}{l}\text { Atmospheric } \\
\text { Water: } \\
\text { Rain }\end{array}$ & $\mid \begin{array}{c}\text { (Country) (Town) } \\
4 \text { or } 5 \\
\text { to } 19 \text { or } 20\end{array}$ & $\begin{array}{l}\text { Amount of dust }{ }^{1} \text {-country } \\
\text { or town. Amount of rain- } \\
\text { fall -with much rain, dust } \\
\text { is washed out of the atmo- } \\
\text { sphere. }\end{array}$ \\
\hline Snow & $\mid \begin{array}{c}(\text { Country) / (Town) } \\
30 \text { or } 40 \text { to } 400 \text { or } 500\end{array}$ & Ditto. Ditto. \\
\hline $\begin{array}{l}\text { Surface Water : } \\
\text { Streams and } \\
\text { pools }\end{array}$ & $\begin{array}{l}\text { Up to several hun- } \\
\text { dred thousand. }\end{array}$ & $\begin{array}{l}\text { Soil from which they drain. } \\
\text { - Amount of organic matter } \\
\text { present to act as food- } \\
\text { supply. Season, tempera- } \\
\text { ture, and rainfall, light } \\
\text { and oxygen, etc. }\end{array}$ \\
\hline Larger rivers & $\begin{array}{l}\text { Several hundreds } \\
\text { or thousands. }\end{array}$ & $\begin{array}{l}\text { Other factors being equal, } \\
\text { the bacterial content of a } \\
\text { largeriverbecomes lessened } \\
\text { by sedimentation, etc., but } \\
\text { may beincreased by sewage } \\
\text { from towns, villages, etc., } \\
\text { on banks. }\end{array}$ \\
\hline $\begin{array}{l}\text { Stored Water: } \\
\text { Lakes and re- } \\
\text { servoirs }\end{array}$ & $\begin{array}{c}\text { Under } 50 \text { to several } \\
\text { thousand (should } \\
\text { not exceed one } \\
\text { or two hundred). }\end{array}$ & $\begin{array}{l}\text { Length of time of storage } \\
\text { and sedimentation. Ab- } \\
\text { sence of organic matter for } \\
\text { food-supply. Character of } \\
\text { source of supply. Season } \\
\text { and rainfall, light, tem- } \\
\text { perature, oxygen, etc. } \\
\text { Presence of Protozoa which } \\
\text { feed upon bacteria. }\end{array}$ \\
\hline Sea-water & $\begin{array}{l}\text { Well under } 20 \text { to } \\
\text { several hundreds } \\
\text { or thousands. }\end{array}$ & $\begin{array}{l}\text { Depth (very few under } 200 \\
\text { fathoms). Distance from } \\
\text { shore. Temperature. }\end{array}$ \\
\hline $\begin{array}{l}\text { Ground Water: } \\
\text { (a) Shallow } \\
\text { open wells }\end{array}$ & $\begin{array}{l}\text { Several hundred } \\
\text { (more if surface } \\
\text { contamination). }\end{array}$ & $\begin{array}{l}\text { Filtering action of layers } \\
\text { through which water passes }\end{array}$ \\
\hline $\begin{array}{l}\text { (b) Sprir } \\
\text { c) Deep }\end{array}$ & $\begin{array}{l}\text { Under } 50 . \\
\text { Well under } 20 .\end{array}$ & $\begin{array}{l}\text { Absence of food-supply. } \\
\text { Absence of surface con- } \\
\text { tamination. Temperature, } \\
\text { absence of air, etc. }\end{array}$ \\
\hline
\end{tabular}

Note.-In estimating the purity or otherwise of a water-supply, not only the number, but the character of the organisms, must be taken into account, e.g. whether belonging to types found in sewage, etc. 


\section{BACTERIOLOGY}

of growing, say in milk, when their less harmful or non-pathogenic relatives are prevented from growing, and by their action in turning the milk sour, warning the housewife that the milk is not fresh.

When we have mastered the technique of sterilisation, we are in a position to collect material containing micro-organisms for purposes of bacteriological investigation. In doing this, we have to avoid contaminating the material with other micro-organisms, both before, during, and after collection ; to avoid killing the organisms we desire to investigate, e.g. with antiseptics or disinfectants, or by heat, or even, in the case of certain very delicate organisms, by keeping them too long or allowing them to get chilled.

Fluids and solid material containing organisms can be collected in suitable sterile receptacles such as a test-tube, flask, bottle, suitably stoppered or sealed, or in sterile cottonwool or gauze. Fluids can also very conveniently be collected in small glass pipettes or tubes, the ends of which can be hermetically sealed in the flame. The specimen should be examined as soon as possible after collection. The systematic examination of such material is then carried out, usually on something like the following lines. Fresh wet preparations are examined under the microscope in order to determine the number, size, shape, and arrangement of the organisms, and especially to investigate whether they possess motility or not. Then smears or films are made on microscopical slides or cover-glasses (usually the former), dried or otherwise fixed, or very thin sections of the tissue containing the organisms are cut by various special methods. These preparations are then stained with suitable aniline or other dyes, often in a very elaborate way, in order to bring out the structure more clearly, or to differentiate one organism from another by such staining reactions. Other means of investigation, such as artificial cultivation, inoculation into animals, etc., will be referred to later.

Morphology and Life-History of Bacteria.-The size, shape, and structure, or as it is usually termed, the morphology of bacteria, may now be considered; and, as we are dealing with such minute objects, we must have some idea of how they are to be examined and measured. Our microscope for the examination of bacteria must be able to magnify them at least about a thousand diameters or more. The standard of such microscopical measurements is termed a Micromillimetre, usually contracted into the form Micro or Micron, and denominated by the Greek letter $\mu$. A micromillimetre is 
equivalent to the one-thousandth part of a millimetre. If those readers who are accustomed to think in British inches will look at a tape-measure or ruler divided into both the British and the metric systems, they will see that an inch contains roughly some twenty-five millimetres, so that a thousandth part of a millimetre will be nearly equal to the one twenty-five thousandth part of an inch. Now, the average bacterium, say a micrococcus, is usually just a little less than one micromillimetre in diameter, so that if one were, in journalistic fashion, to imagine a straight row of them side by side across a halfpenny piece, which measures exactly an inch in diameter, it would take a line of more than 25,000 of them to stretch right across it-a fact which gives one some idea of

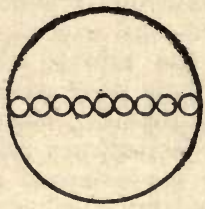

a.

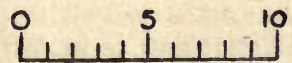

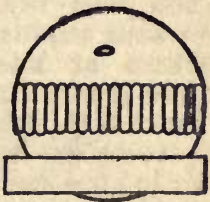

b.

1

Fra. 8. -The two larger circles represent the size of a red bloodcorpuscle magnified about 2500 diameters. (a) Chain of nine average-sized micrococci. (b) Eighteen average-sized bacilli placed side by side across a red blood-corpuscle. Above and below these are drawn an influenza and an anthrax bacillus respectively.

(Erach small division on the scale represents a micromillimetre magnifled 2500 times.)

their extreme minuteness. For anyone accustomed to the use of the microscope and who knows what a red bloodcorpuscle is like, another useful rough-and-ready standard of comparison can be suggested. A red blood-corpuscle is a small, flattened, disc-like object about seven or eight micromillimetres in diameter, so that we can realise the average size of a coccus by imagining eight or ten of them placed in a row across its flat surface. It has been estimated that it takes $10,000,000,000$ average-sized bacteria to weigh one milligramme, i.e. $\mathbf{a}$ thousandth part of a gramme or one sixty-fourth part of a grain in our measure!

Bacteria, of course, vary considerably among themselves in size. The average rounded Bacterium or Coccus is, as we have seen, about 0.8 or $0.9 \mu$ in diameter; and an average rod-shaped Bacterium or Bacillus is about $0.5 \mu$ in breadth, and about 2 or $3 \mu$ in length. The influenza bacillus is much smaller, 
and the anthrax bacillus considerably larger than this, and in the accompanying figure will be found a diagrammatic representation of these organisms compared, as regards size, with red blood-corpuscles, each being magnified about 2500 diameters.

In this connection we may recall the fact already mentioned on page 10 that, of certain other organisms, the filter-passers, the majority are still invisible even with this high magnification; though at all events one of those so-called filter-passers, the organism of contagious pleuro-pneumonia in cattle, is just visible under the highest powers at present available. This organism is a little over a tenth of a micromillimetre in diameter, which measurement, i.e. $0 \cdot 1 \mu$, has been calculated to be the limit beyond which our present-day microscopes cannot render objects visible.

Structure of Bacteria. ${ }^{1}$-Owing to the minute size of bacteria it is very difficult to make out their finer structure. They consist of semi-fluid, jelly-like protoplasm, clear, refractile, more or less homogeneous, or sometimes slightly granular in appearance. The outer layer is condensed into a firmer "skin" - the cell-wall or cell-membrane-which does not consist of cellulose as is the case with vegetable cells. There is no nucleus present, as there is in the higher animal and vegetable cell, the nuclear material or chromatin, so called from its affinity for various dyes, being scattered diffusely or in granules, or sometimes aggregated towards certain partsespecially the ends-of the bacterial body. The presence of droplets of fat and granules of various substances such as sulphur, starch, glycogen, etc., may in some cases be demonstrated by their chemical reactions; and pigment granules or particles of coloured material are sometimes found.

Young and actively growing bacteria usually show a welldefined and regular contour, but when old, or placed in unfavourable circumstances, they show various degenerative changes, such as irregularities in size and shape, vacuolation (i.e. the appearance of small areas like empty holes in the protoplasm - not in reality empty as the name would imply, but filled with clear, colourless fluid), alterations in their staining capacity, and other changes.

Many bacteria are actively motile, i.e. can themselves travel in a fluid medium; others do not possess this capacity. Such motility must not be confused with passive convection or carriage of contained bacteria by currents in a fluid, or by the fluid itself travelling from place to place, as in the case of a

3 For many of the points here described, see Frontispiece. 
river or drainage-water, or where microbes adherent to dustparticles or the like are carried by the wind or in some other way. In a suitable stationary fluid, the actively motile germ of typhoid fever can travel about four millimetres (a little less than a sixth of an inch) in an hour; whilst the extremely active cholera organism may cover something like eighteen millimetres, or about two-thirds of an inch, in a similar time. From this it will be seen that the practical question of the passage of bacteria from place to place, e.g. in the spread of epidemics, is one of passive carriage in water or milk or dust, in contaminated clothing or excretions or the like, rather than of active locomotion by the bacteria themselves.

Motility is usually, though not always, due to the bacterium possessing one or more, and sometimes numerous, long, delicate, vibratile, hair-like organs called flagella ("little whips")
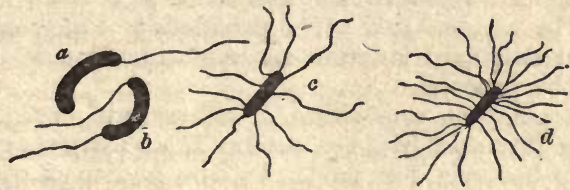

FIG. 9.-Examples of Flagellated Organisms. (a) Cholera Vibrio with a single terminal flagellum. (b) Vibrio of another species with a terminal flagellum at each end. (c) and $(d) . B$. Coli and $B$. typhosus, with many flagella all round, those of the latter being most numerous.

or cilia ("hairs"), by means of which it swims in the fluid; and there is often also an active wriggling eel- or snake-like movement of the body of the organism as well.

Some bacteria, for example the Pneumococcus (which causes, amongst other diseases, acute lobar pneumonia), possess what is called a capsule, sometimes of considerable thickness. This investment is probably formed by a modification of the outer part of the cell-wall, and is doubtless protective in its function. Many bacteria also secrete or produce a viscid or jelly-like material resembling mucus, amongst which they are found embedded, and which often serves to glue them into masses; and this intercellular substance, as it is called, may partly account for the arrangement of bacteria into the characteristic grouping illustrated in the Frontispiece, figs. 1 to 6.

The method and rate of reproduction of bacteria are matters of great interest; and we have already seen that, as their scientific name, Schizomycetes or fission-fungi, implies, it is by direct division, fission or splitting-septation, as it is sometimes called-that multiplication occurs. Under favourable 
circumstances, e.g. with a suitable food-supply, temperature, etc., this division may occur on the average about once in twenty to thirty minutes, so that, if there were no factors acting to delay or prevent such multiplication, a single organism would give rise, in the course of some ten hours, to a progeny of a couple of millions, or, in twenty-four hours, to the inconceivably huge number of $75,000,000,000,000$ offspring ! Fortunately, however, Nature interposes many checks and barriers to restrict this unlimited multiplication-for, if she did not, there would be room for nothing but bacteria on the face of the earth. Chief among such barriers are limitation of the food-supply, and the production by the bacteria themselves of excretions and by-products which hinder or inhibit their further multiplication. Thus in alcoholic fermentation there is active proliferation as long as there is plenty of the sugar or other substance for the bacteria to feed upon, and also until the alcohol and other products of their activity are produced in sufficient amount and concentration to automatically stop the process.

There is also the opposition of other living creatures, for many lowly forms of life, e.g., among the Protozoa, prey upon and devour bacteria for food. In the bodies of the higher animals there are also forces of opposition to the attack and multiplication of bacteria, which will be described in our Chapter on Immunity (p. 42).

Not only so, but, even in favourable circumstances, the rate of bacterial production is not mathematically constant. There is usually a short period of slow growth whilst initial difficulties are being overcome and the organism is accustoming itself to its surroundings. Then, if these are successfully overcome, there is a varying period of rapid and active proliferation, which, unless the surroundings and food-supply are renewed, gives place to a stationary period, and then, after a varying time, to the decline and ultimate death of the bacteria. This process in many ways resembles what is seen in the growth, decline, and extinction of, say, a nation of human beings, if restricted to a limited area, though here, of course, other higher laws also come into play. Some races of bacteria are much more resistant than others. Some can live and be grown only with the greatest difficulty upon artificial media-dying off, perhaps in a few hours or days. Others are very hardy, and can live, for example, in a culture-tube, for months and even years. Some, again, have developed special methods of resisting adverse conditions. This is notably the case with those organisms which form spores, such as the bacilli which cause Anthrax ("Splenic Fever" of cattle), Tetanus or Lockjaw, and 
others. This is not a reproductive process, but a protective and resistant one, whereby the protoplasm or living substance of the bacterium becomes condensed and surrounded by a thick capsule-like condensation or cell-wall. Such spores, or endospores, to give them their full name, can live without food or water for long periods-sometimes for many years-and can

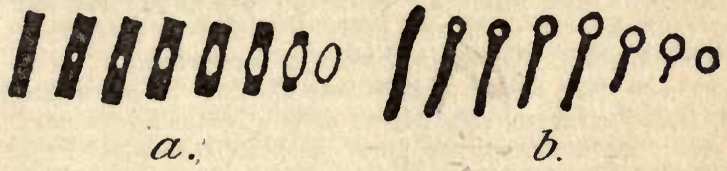

FIG. 10.-(a) Spore Formation in Anthrax(b) in Tetanus Bacilli.

even resist boiling and strong disinfectants for a considerable time (see under "Sterilisation" p. 26).

Somewhat analogous protective and highly resisting stages may occur in Protozoa (encystment, etc.), and even higher up the scale, e.g. in the case of certain parasitic worms. When the bacterial spores find themselves again in congenial surroundings, e.g. in suitable conditions as regards food-supply, moisture, and temperature, they can then germinate, i.e. the spore-capsule bursts like a seed-cover, and the contained germ of protoplasm escapes and re-grows into the ordinary or "vegetative" type of organism from which it arose.

The Artificial Cultivation of Bacteria.-One of the most important methods of studying bacteria istogrow them artificially in or upon various suitable nutrient culture-media.
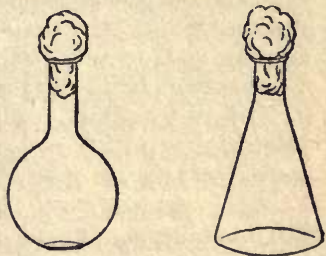

FTa. 11.-Glass Flasks plugged with cotton-wool. These are used for the making and storing of culturemedia, etc.

Many different oulture-media are employed. Some bacteria will grow in a medium containing the chemical elements of their protein constituents (i.e. the elements of which their protoplasm is composed, such as carbon, hydrogen, oxygen, nitrogen, etc.), in solutions of acetates, and other organic salts. Usually various animal fluids, either natural or prepared, are employed - for example, blood-serum, milk, meat-broth, or bouillon. Meat-extract is the commonest basis employed, and as in its preparation some important constituents of the animal tissues from which it is made are lost, e.g. some of the salts and proteins, these are usually replaced by the addition 
of a proportion of common salt and peptone, the latter being a soluble protein substance prepared by artificial digestion. It does not coagulate on heating the fluid, and it is therefore used to replace those protein substances which have been coagulated and lost in the preparation of the meat-extract. For full details of media-making reference must be made to larger text-books. The nutrient broth so prepared may be used alone; or gelatin or agar ${ }^{1}$ may be added to convert it into a nutrient jelly. Glycerine, various sugars, and other substances are often added to facilitate the growth of the bacteria, or to test the fermenting action of the bacteria upon such substances. Most organisms grow best in a neutral or faintly alkaline medium, though a fow prefer a faint acidity; and therefore the reaction of culture media is carefully adjusted, litmus or some other indicator being used.

Slices of potato and other vegetable tissues are often also used, and bread-paste is a useful medium for growing moulds. Numerous special media, often highly complex in their composition, are also used for special bacteria. Sometimes substances are added to prevent the growth of one type and help the growth of another.

Dead animal tissues, ${ }^{2}$ partially or wholly immersed in suitable fluid, are also now used to grow special organisms upon, e.g. the tubercle bacillus, and also certain of the disease-producing Protozoa, and this method has recently led to some important advances in our knowledge of such organisms, and will probably lead to advances also in the immediate future in our methods of diagnosis and treatment of many diseases. Various observations of great importance can be made upon the life-history of organisms under artificial cultivation. Some grow easily, others only with difficulty or not at all. The medium employed must be suitable, and for the more delicate bacteria special substances or special media may be required. Thus the influenza bacillus and some of its relatives require the presence of haemoglobin or the red colouring matter of the blood. The tubercle bacillus will not grow upon ordinary media, but will grow upon egg or blood-serum, or upon other media to which glycerine has been added. Some organisms require the presence of oxygen, and are therefore known as

1 Agar, or agar-agar to give it its full name, is a substance obtained from certain seaweeds which grow in the Far East. It is used when a jelly which does not melt too easily is required.

2 It is interesting to notice in this connection that small pieces of living animal tissues, if carefully removed and immersed in blood-serum, may themselves survive in artificial "culture" for several days or weeks, and may even proliferate or grow in an irregular fashion. 
aerobic; whilst others will grow only in its absence, for example the anaerobic Bacillus tetani, the cause of lockjaw or tetanus. Many, however, can flourish under either condition.

The best or "optimum" temperature, as well as the maximum and minimum at which organisms will grow, has to be studied. Most disease-producing bacteria grow best at the body temperature of their hosts - in the case of man, $37^{\circ} \mathrm{C}$. Organisms of putrefaction such as are found in water, soil, etc., grow at ordinary temperatures, but flourish most abundantly at summer heat, and it is, of course, common knowledge that meat, milk, etc., "go bad" much more rapidly in summer than in winter, "keep" best if kept cool, and indefinitely if frozen. Such freezing, however, does not kill the majority of bacteria, but only "inhibits" or prevents their activities. Even prolonged exposure to temperatures far below $0^{\circ} \mathrm{C}$. $\left(32^{\circ}\right.$ F.) has little effect on their vitality. Certain thermophilic or heat-loving bacteria can live at comparatively high temperatures, for example those found in hot springs, and in hot beds of decaying organic matter, and to the activities of these, amongst

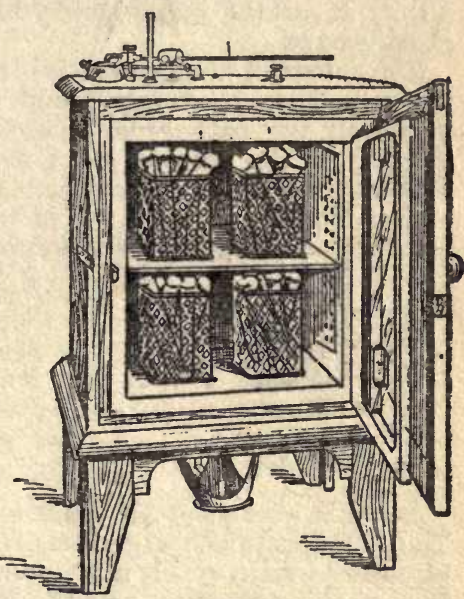

FIG. 12.-Biological Incubator, for the cultivation of micro-organisms in which cultures may be grown at a suitable temperature, usually $37^{\circ} \mathrm{C}$.

other factors, is due the "heating" of haystacks, manureheaps, etc.

The thermal death point, or the temperature at which they are destroyed, has already been alluded to under Sterilisation (p. 24).

The actual size, shape, colour, method of spread, and other physical characters of the colonies or masses of bacterial growth in culture are of considerable importance in identifying bacteria. They depend to some extent on physical conditions, e.g. temperature, nature of the nutrient medium employed, and the amount of moisture present; but under similar conditions, an organism tends usually to show the same characters more or less constantly. Members of the 
same group of bacteria frequently show a very similar appearance on culture, and require special tests for their differentiation. In a fluid medium such as nutrient broth, the organism may produce a general turbidity, or it may grow as a scum on the surface, or as a deposit at the bottom. On the surface or in the substance of a jelly, typical appearances are often seen; and, if gelatin be the substance employed to make the jelly, some organisms are found to liquefy it by the action of digestive ferments which they produce, whilst others do nota very important test whereby bacteria are divided into two great groups.

The colour of the growth is often characteristic. Many of the organisms commonly found in air and water, but comparatively few pathogenic bacteria, produce brightly coloured growths. The various tints formed by such chromogenic bacteria include all the colours of the spectrum, and the following interesting table (taken from Frost and M'Campbell's General Bacteriology) gives one example of each :

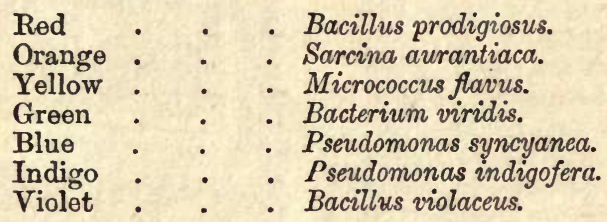

Bacteria producing all the intermediate shades are known. The first-mentioned organism, $B$. prodigiosus, produces a rich blood-red colour, and it is supposed to have been the explanation of the "bleeding bread" of the Middle Ages. The pigment produced by chromogenic bacteria may be contained in their substance, or may be excreted into the surrounding medium.

Fluorescence-a peculiar bluish appearance on exposure to light-is seen in some cultures; and phosphorescence or light production is also caused by some bacteria, as well as by certain Protozoa and moulds. The latter process is really a slow combustion or burning up of organic matter, and an abundant supply of oxygen is required for its production. Such phosphorescence is a common phenomenon in sea-water, and it may also often be well seen in decaying animal or vegetable material.

Some media are coagulated by the action of bacteria, the most familiar example of this being the curdling of milk. The chemical action of bacteria upon their surroundings is a very complicated subject, and it is sufficient to say here that many 
highly complex organic compounds are split up into simpler substances by a process akin to, or in some cases identical with, digestion. Proteins, sugars, starch, etc., may be attacked by such fermenting organisms. Various gases are often given off during the process, carbonic dioxide gas, nitrogen, hydrogen, marsh-gas and sulphuretted hydrogen being amongst the commonest of these (see Fig. 13, d). The bubbles rising to the surface of stagnant water from the decaying matter at the bottom, and the collection of gases in the intestine, are familiar instances of this process. In some forms of gangrene, e.g. in Malignant Oedema, the tissues of the living body are attacked bygas-producing organisms; and gas-production is practically always present in the decay of the body after death unless prevented artificially or by special climatic or other conditions. It is by this means that dead bodies immersed in water come to the surface after a varying interval. Sometimes, during the last hours of life, when the tissues of the body are devitalised by illness, putrefactive bacteria from the intestine and elsewhere pass into the bloodstream and spread through the organs and tissues.

Fermentation.-Various alcohols are produced by micro-organisms, usually belonging to the yeasts, though numerous bacteria also produce alcohol in small quantities. Certain organic acids are important

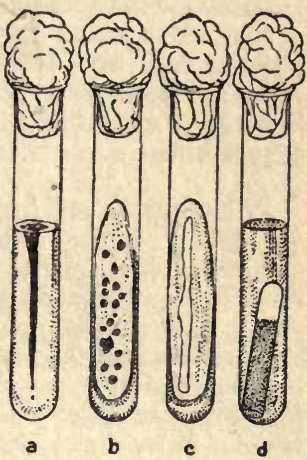

FIG. 13.-Cultures. (a) Stabculture in nutrient gelatin. The dark part represents the bacterial growth in the substance of the jelly. ( $b$ and $c)$ Surface-cultures on sloped agar, (b) showing scattered colonies, (c) a line of growth. (d) Fluid culture, showing fermentation with'gas-production, the gas being caught at upper part of small inverted tube. by-products of fermentation, and are especially produced by the splitting up of various sugars. Thus lactic acid is formed by the splitting up of milk-sugar, about a hundred different species of bacteria having this action being known. Other by-products are usually produced at the same time, but generally in smaller amount than the lactic acid-e.g., acetic and formic acids, etc., as well as various gases and alcohols.

Acetic acid, the most important constituent of vinegar, is a common product of the fermentation of various sugars, the formation of alcohol being an intermediate stage in the process. A free supply of oxygen is necessary for the action of acetic 
acid-producing bacteria, and, if the process is carried further, the acetic acid itself may be broken up to form water and carbonic acid gas (carbon dioxide).

Butyric acid is similarly produced by a corresponding group of bacteria which can attack almost any sugar or allied compound, glycerine, and also in some cases proteins and fats. Sour milk usually contains not only lactic but also butyric acid so produced.

These three forms of fermentation-lactic, acetic, and butyric - very often occur in the stomach in cases of chronic indigestion, and are due to the action of the specific bacteria upon the retained food-various gases such as carbon dioxide, hydrogen, etc., being also produced, causing distension and eructations.

Putrefaction and decay of dead animal and vegetable matter are highly complex processes which may here be shortly discussed. Living plants and animals have the faculty of resisting more or less completely the attack of bacteria; but after their death, the complex compounds of which their tissues are built are speedily attacked and broken down into simpler substances in much the same way as food is digested, i.e. by the action of ferments-in this case produced by the bacteria. Organisms which can live upon such dead organic matter are called saprophytic (Greek: sapros, rotten, and phyton, a plant). Those which actually cause the breaking up of the organic matter are called saprogenic (Greek : sapros, rotten, and genes, producing); and there are also numerous bacteria, moulds, etc., which can live upon the products of putrefaction, and which are therefore called saprophilic (Greek : sapros, rotten, philein, to love) ; though in many cases both functions are combined. Putrefactive processes go on most readily in absence of oxygen, i.e. the majority of saprogenic bacteria are anaerobic, and the products often have a very foul smell, especially those containing the aromatic and sulphur constituent of the original protein. Sulphuretted hydrogen, indole and skatole, are amongst the substances so produced, and to them is due the characteristic odour of animal excrements and other decomposing matter.

Where abundant oxygen has access, the process is somewhat different, and is sometimes known as decay, the products being more freely oxidised and the odour much less marked. These changes and the substances so produced from proteins, carbohydrates, sugars, etc., can be studied in the eulture tube, and by their nature the differences in the action of the special bacteria under investigation can be used as mathods of identification of these bacteria. 
Amongst bacterial products, certain extremely poisonous substances, many of them of more or less unknown chemical nature, are of extreme importance, especially in the case of pathogenic or disease-producing organisms. The origin and actions of these poisons are very varied. Thus they may be ferments or enzymes secreted by the bacterium for the purpose of attacking and digesting its food, they may be excreted as waste-products of bacterial metabolism or cell-life, or they may be derived from the disintegration of the food material attacked by the organism. Ptomaines are poisonous alkaloidlike substances formed in decomposing meat, fish, and the like. They are not destroyed by cooking, and hence may cause one form of "food-poisoning." Botulism (Latin : botulus, a sausage), or poisoning from eating infected sausages or similar foods, often fatal in its effects, is of this nature, a specific anaerobic organism, Bacillus botulinus, being the bacterium which produces the poison.

1. Toxins, on the other hand, are the specific poisonous products of bacterial metabolism or cell-life and growth. They are sometimes retained within the bacterial bodies and are then called endo. toxins; whilst others again are secreted into the surrounding media, whether in the living body or in the culture-tube. The best known and most extensively studied examples of the latter-the extracellular toxins - are those produced by the tetanus bacillus and the diphtheria bacillus. These are soluble and diffusible, and, if formed in the living body, they pass into the lymph and blood and produce their serious results by poisoning the tissues. Their exact chemical nature is still unknown. They are very unstable, being easily destroyed experimentally by heat or light, or by being kept for a long time.

Isolation of Bacteria in Pure Culture.-This is usually attained by separating the bacteria in a given mixture, either by smearing a minute quantity of it over the surface of a solid culture-medium, or by diluting it with a sufficient amount of melted nutrient jelly, which is then poured into a sterile Petri dish (see Fig. 14), and allowed to solidify. After incubation at a suitable temperature, if sufficient separation of individual bacteria has been effected, scattered colonies, each consisting of one variety of organism only, will be found, and these can be individually picked off and subcultured in fresh culturetubes. 
Other methods of isolation may sometimes be employed, for example, less resistent organisms in a mixture may be killed off by graduated heat (see p. 27) or by chemicals; or animals susceptible to the special bacterium may be inoculated, and the organism "recovered" from their tissues.

\section{CHAPTER V}

\section{HEALTH AND DISEASE}

The Relations of Bacteria to the Living Body and to the Production of Disease-Susceptibility and Immunity

As we have already seen, bacteria of various kinds are present in enormous numbers upon the surface of the body and in the mouth and other parts of the alimentary canal. How are they prevented from obtaining access to and invading the blood and the tissues of the body, which are normally free from them? Microbes, like the poor, are always with us. We all have pneumococci and numberless other organisms in our mouths and throats. The tuberclo bacillus in the present stage of our civilisation is present in the sputum-contaminated dust of our towns and in our milk-supplies. Tetanus bacilli lurk in our gardens and fields and on our roads. Staphylococci in crowds lie on our skins, and our bath-water contains them by the million after every ablution-and yet some of us at all events, manage to resist their attacks, whilst others are caught unprepared and suffer accordingly, and some are "never well."

By Immunity against Infective Disease is meant the power of resistance against such attack by pathogenic microorganisms of all kinds. It is an extraordinarily complex process, of which science has only just begun to unravel the elements. The perfectly healthy body, by means of its specially evolved covering and "linings" - the skin and mucous membranes-can prevent the entrance of organisms; but few or none can boast of "perfect health." Some damage to these surfaces may allow of the entrance of organisms at any moment, and at any part of the bodily surface (and for our purpose here, and scientifically speaking, the mucous membrane, say of the stomach or intestine, is just as much a covering or surface as the skin, the food being really "outside," i.e. not within the tissues of) the body. Such damage may be produced by any number of causes. Mechanical injuries such as cuts or scratches, abrasions and even bruises, may allow the microscopic invader to enter-or it may be that a mucous membrane is damaged 
by a "chill," by unsuitable food, by nicotine or alcohol, or by some other poison; or the power of resistance may be lessened by other diseases, by old age or the like.

During or after its entrance into the tissues, the bacterial or other intruder has to be attacked, and weakened or killed, removed from the tissues, and expelled; and there are two chief factors in this defensive process. Phagocytosis (Greek: phagein, to eat, liytos, a vessel or cell) is a function of many of the constituent cells of the animal body. Not only the wandering white cells, or leucocytes of the blood, but also the cells lining blood- and lymph-vessels and the serous sacs around the internal organs; the cells of the many glands of the body, e.g. the liver; the cells in connective tissues, etc. ; have the power of ingesting, englobing, or engulfing foreign particles such as bacteria, and digesting them. The most picturesque and most easily studied of these phagocytic cells are the leucocytes of the blood. The most numerous of these are the polymorphonuclear leucocytes, one of whose most important functions is the attacking and ingesting, and if possible digesting and destroying, of any invading bacteria. Certain other leuoocytes, the large mononuclear cells, are also very important phagocytes. They too take up bacteria, but one of their characteristic functions is the attacking and englobing of protozoal parasites such as the malarial parasite; and they also take up and digest any of their polymorphonuclear brethren that are injured in the fray. For full details of the process, reference must be made to books on Pathology. Phagocytosis is really a special instance of the way in which a simple cell such as a protozoon (e.g. the amoeba) obtains its food. It approaches its prey, drawn by some subtle and as yet littleunderstood influence, to which the name chemiotaxis has been given, and may paralyse or otherwise affect it by means of ferments which it secretes. It then pushes out around it armlike processes of its protoplasm called pseudopodia (Greek: pseudes, false, pous, a foot), draws its prey within its cell-substance, and proceeds to digest it by means of ferments.

Besides these phagocytic cells, there are, in the blood and other body fluids, innumerable chemical substances, many of them of the nature of ferments, which are elaborated by the various cells for the purpose, amongst other things, of affecting any bacteria or other hostile cells which may have gained entrance. Many of these substances are normally present in the healthy animal, but a large number of them are specially developed only after the hostile agent has gained an entrance, and are specific only against the special variety of bacterium or protozoon concerned. The new-born child inherits a certain 
number of these antibodies, as they are called, but many others it has to elaborate for itself as the result of experience. The function of these antibodies is probably, as in the case of phagocytosis, merely a modification of the natural process of food-digestion; and the infant has to learn to become immune, not only to bacteria, etc., but to the various kinds of food upon which it must acquire the capacity of living. A certain amount of such immunity is transferred by the mother to her infant before birth, and also by her milk, but after birth the child's tissues have to learn to fight their own battles against the bacteria which speedily gain access to its skin and alimentary tract. Normally this process is a gradual one; the tissues learn their lesson and the invaders are kept out ; but, if the child is feeble, if disease-producing organisms are present in its food, and especially if that food be abnormal, and if other factors are unfavourable, such as absence of light and air, etc., its powers of resistance are unequal to the strain, the bacteria gain entrance, and the child becomes ill, i.e. the fight becomes so intense that the symptoms we are accustomed to associate with illness manifest themselves-symptoms which are often rather a sign that the fight against the invader has become more severe, than that the illness has just commenced. In the case of many of the specific infective fevers of childhood, e.g., Scarlet Fever, Measles, Whooping-Cough, etc., once the struggle is successfully over, a more or less lasting and complete immunity against that special disease is established. Similarly, one attack of Smallpox protects against another attack. Unfortunately, however, there are some diseases after which the period of immunity is short or even absent. Influenza, Pneumonia, and many forms of Common Cold are frequently followed by relapses and recurrences. Some diseases also, by their weakening action upon the body, render the tissues more liable to invasion by other organisms, and it is for this reason that Measles and WhoopingCough, Pneumonia and Influenza, are so often followed by broncho-pneumonia, or by tuberculosis, these diseases preparing the way, and rendering more easy the entrance and multiplication of strepto- and pneumococci or of the tubercle bacillus.

Immunity, like pathogenicity or the power of the attacking organism to produce disease, is relative and not absolute. If an organism capable of producing disease passes through a series of relatively susceptible animals, it usually becomes more and more virulent, i.e. its power of attacking and causing disease in such animals is increased. This is one important factor in the production of some epidemics such as influenza, where the organism passes directly from host to host, for instance in the fine spray produced by coughing or sneezing. 
Similarly an organism possessing the same degree of virulence may cause little or no effect in one person whose immunity or power of resistance is relatively high ; it may produce a slight attack of disease in another whose immunity is less marked; and a severe and perhaps a rapidly fatal illness in a third whose vitality is lowered by various causes such as those enumerated above, or who does not possess a certain degree of natural immunity against the disease. In these instances we have been discussing individual immunity, but there is also such a thing. as family and race immunity, and again some animals are liable to, whilst others are relatively, or even almost absolutely, inmune to certain diseases. Thus, foul-feeding animals such as fish, vultures, ravens, and carnivorous animals in general are relatively immune to bacterial infection. On the other hand cattle, and some rodents, especially guinea-pigs, are extremely susceptible to tuberculosis and anthrax, rabbits and mice to infection with the pneumococcus, and so on.

In the same way certain races of mankind are more immune or more liable to certain diseases than others. One well-known example of this is, when civilised races have invaded and colonised the countries of other and simpler nations, the "diseases of civilisation" have in many cases decimated and in some instances almost annihilated the latter. Thus tuberculosis is specially virulent amongst negroes ; and a somewhat similar phenomenon was seen during and after the South African War, when measles in a very virulent form broke out among the Dutch population, particularly in the concentration camps, and carried off many victims who had not in infancy contracted the disease and so become immune, as is generally the case amongst ourselves. Again, diseases to which the native population may be partially or almost entirely immune, probably partly by heredity and partly through having overcome the disease early in life, may attack the invading races with special virulence. Malarial and yellow fevers may be instanced as examples of this.

Many diseases are common to men and animals; e.g. tuberculosis, plague, and the like. Some infections such as glanders and anthrax are found amongst animals, but are occasionally communicated to man; and again man is practically immune to certain animal diseases, such as hog- and chicken-cholera; whilst such human diseases as measles, whooping-cough, yellowfever, syphilis, gonorrhoea, etc., do not naturally attack the lower animals.

Infective disease is, then, merely one instance of the struggle in nature, wherein one living being preys upon another for food; and in this case it is the attack of the relatively small 
upon the relatively large. It behoves the relatively large therefore, and man amongst their ranks, to keep their defences in the highest state of efficiency. Just as a nation which becomes opulent and lazy, and refuses or forgets to keep its constituent units in training and its defensive resources over in readiness - even though it may appear to live for a time in safety-is surely and inevitably attacked and overcome by a foreign foe; so is the body of the individual, whose tissues and cells have not learned to fight the invisible but ever-present foes around him, certain to be attacked sooner or later. A man is "ill," not merely when and after the visible symptoms of his disease are upon him - that is only when his fight against his enemies has become more acute-but he is already ill, and perhaps seriously and critically ill, during the incubation or latent period of his disease, when the invader has already entered his territory unknown to him and is spying out his weak places. His outlying fortifications, his skin or his mucous membranes, have already been stormed. He must then, if health is to be preserved or restored, have at his disposal an efficient regular mobile army, the leucocytes of his blood both large and small, ready to rush to the point of attack. His Territorials too, the local cells of his tissues, must be ready to take their part in the fight. His roads and railways are his blood and lymph-vessels, the lines of communication which carry his fighting forces. His training schools and recruiting stations are in the marrow within his bones (where most of his active fighting blood-cells are produced) as well as in other tissues - his spleen and his lymphatic and other glands, where fighting cells are also present which may seize upon and destroy any of the invaders which reach them. The weapons too must be ready-not only of defence but of offence-his bullets and his bayonets are his various ferments and antibodies, such as antitoxins to neutralise the poisonous toxins of the invading bacteria: antibacterial or bactericidal ferments to attack the bodies of his foe, agglutinins to paralyse them, bacteriolysins to dissolve and disintegrate them, and a thousand other subtle and as yet little-known substances with which the wonderful nation of his body-cells is equipped for the fray. This is not all mere journalistic imagery, but stern reality, and in this battle no quarter is given on either side. Even amongst his own troops, no mercy is shown to the weak or to the severely wounded. Leucocytes which have done their duty and have suffered in the process and are beyond recovery, are simply eaten by their larger brethren on the spot, or in some of the organs to which they are carried, or they are discharged altogether from the body along with bacteria and broken-down tissues in the form of pus. 
For a fuller account of this, aspect of the subject, for details of the processes of inflammation, repair, and recovery, reference must be made to the larger textbooks on Pathology.

Immunity, then, is a relative question. When an animal is not susceptible to a given disease, it is said to possess a natural immunity against that disease. On the other hand, immunity may be acquired, sometimes by a process of gradual training analogous to the gradual immunity acquired for certain drugs such as opium, arsenic, alcohol, or tobacco ; in other cases by having a single attack of the disease.

Experimental or artificial acquired immunity is a very important and interesting branch of the subject. In the animal body we may produce what is called active immunity by introducing the causal bacteria themselves, alive, weakened, or dead, or their products. The deliberate inoculation of living virulent bacteria, even in minute doses, is of course always a risky proceeding, and is now practically never carried out in the case of man himself, though this was one of the earliest methods to be employed, as, for instance, when the virus from the smallpox pustule was inoculated directly into the healthy person in the hope of producing a mild protective attack of the disease-a method introduced from the East into this country by Lady Mary Wortley Montague, but soon discarded and prohibited by law owing to its dangers.

The first great advance in such prophylactic or preventive inoculation was Jenner's discovery of Vaccination, cow-pox being caused by an organism closely allied to, or very probably identical with, that of smallpox, but so much weakened by its passage through the cow as to be practically harmless to man, yet producing a sufficient reaction in his tissues to establish a very marked immunity against the terrible scourge of smallpox itself.

The term "Vaccination" has now been extended to include the artificial inoculation of the weakened or dead organisms of any of the infective diseases, and such methods are extensively used as a protective measure for those who are liable to be exposed to infection by typhoid fever, plague, and several other diseases. Similarly, Vaccination may also be used in many instances as a therapeutic measure, i.e. in the treatment of a disease already present. Extraordinarily good results have been thus attained in the treatment of boils and pustules and other infections due to Staphylococci, especially in some of the chronic cases which resist the ordinary modes of medical and surgical treatment. Many other diseases are also now so treated, especially when the organism is more or less localised, 
e.g. common colds, sore throats, bronchitis, gleet, cystitis, etc., though in some conditions the results have not come up to expectation. The method is really that of stimulating the defensive powers of the patient and teaching his tissues to help and defend themselves. The various methods of treating tuberculosis by the tuberculins is of this nature, and, though to some extent it is not yet beyond the experimental stage, something may still be hoped from it in the future.

Another important way of conferring immunity, quite different from the above in its mechanism, is known as passive immunity. In this form, the substances or antibodies already produced by another animal are withdrawn, usually in its blood-serum, and then injected into the animal or patient to be protected against the same disease as that against which the first animal has been actively immunised. This method is sometimes employed for obtaining immunity against bacteria themselves, and sometimes against their toxic products only. These are known respectively as antibacterial and antitoxic sera. As examples of the former of these, anti-streptoccccal and anti-plague sera, and of the latter, anti-diphtheritic and anti-tetanic sera may be mentioned, and it will be obvious that the chief use and value of these anti-sera will be for the treatment of diseases already present. Antitoxic sera aid by neutralising the toxins of the bacteria; anti-bacterial sera attack the bacteria themselves, both thus protecting the tissues of the patient and giving him a better chance of fighting the disease. Their action is more or less transitory, and repeated injections of the serum may be required. Protective inoculation by anti-sera is also useful where persons have been or are likely to be exposed to infection, or are suspected to be in the incubation or preliminary latent period of a disease such as diphtheria or tetanus.

A promising new line of treatment now being tried is the combination of a vaccine and its corresponding anti-serum inoculated at one time into the patient to be protected.

\section{CHAPTER VI}

MODES OF THE ENTRANCE OF PATHOGENIC BACTERIA INTO THE BODY, AND THEIR ACTION

How can we determine that a certain organism is the cause of a given disease? At the beginning of the "bacteriological era," when pathogenic bacteria were first isolated and identified, Robert Koch set forth certain postulates, usually known 
by his name, which had to be fulfilled before the chain of evidence in a given case could be regarded as absolutely complete.

1. The organism must be found constantly present in the tissues of the affected animal, in the same relationship, and in the same kind of disease.

2. The organism must be capable of being isolated from that animal, and grown in pure culture artificially outside the body.

3. The organism so isolated and freed from all other organisms and from any trace of the tissues of the original animal, must be capable of producing the disease when inoculated into a second susceptible animal.

4. The organism must then be found in and be recoverable from the tissues of this second experimental animal.

The great majority of disease-producing bacteria completely fulfil the demands of these postulates. A few still do not, sometimes for lack of a susceptible animal other than man, sometimes for lack of a suitable artificial culture-medium; but this list is rapidly diminishing as scientific methods of experimentation are being steadily improved. In addition to Koch's postulates, the evidence of other methods, based on our knowledge of immunity, is now utilised; for example, the Agglutination Test, in which the bacteria are aggregated or clumped together by the action of the serum of an animal or patient suffering from the specific disease caused by that bacterium, e.g. Typhoid and Mediterranean Fevers, etc. In another such test, the bacteria are paralysed and disintegrated by the corresponding serum, as in the case of cholera-a process known as Bacteriolysis. Another extremely important test is known as the Deviation or Absorption of Complement-a very complicated reaction of which mention can only be made here, and the best-known example of which is the now well-known Wassermann Reaction for the diagnosis of Syphilis. (For a description of these and other refinements in modern diagnostic methods, such as the Precipitin, Absorption, and Anaphylactic Reactions, reference must be made to the larger textbooks.)

Methods of Entrance of Pathogenic Organisms into the Body.-As already mentioned, many organisms capable of causing disease are already harboured upon or in the body, and only require the assistance of some damage such as a wound or scratch or burn, or of some cause predisposing to the weakening of the tissues, say of the alimentary or respiratory tracts. Organisms already present in the skin or mouth, intestine or elsewhere, may thus become pathogenic when the patient's vitality is lowered. The Pneumococcus may cause a sore throat, a bronchitis, or a pneumonia. Staphylo- 
cocci and Streptococci similarly may cause abscesses, catarrhs, or other forms of inflammation. Dirty or decaying teeth, suppurating gums, enlarged tonsils, and the like are extremely common sites of infection, and proper hygiene of the mouth is one of the best ways of avoiding disease in its many forms due to oral sepsis. In this connection it must be remembered that a toothbrush at once becomes septic after use, and may subsequently cause infection by scarifying the gums. The brush should therefore be rinsed after use in one per cent. trikresol solution. Some of the many organisms in the mouth or intestine may increase in numbers and attack the tissues and perhaps invade them and even spread throughout the body, producing what is called a septicaemia, i.e. the presence of organisms in the blood; or they may pass through the damaged walls, say, of the intestine and cause appendicitis or peritonitis. They may thus pass from one position in the body, where they are comparatively harmless, to another where they cause disease.

Again, bacteria may be inoculated or implanted into the tissues from without. The bite or scratch of some animal with contaminated teeth or claws, or the bite of some blood-sucking insect, are very important means of spreading disease. Rabies or hydrophobia, as is well known, is usually the result of the bite of a mad dog or wolf or other animal itself the victim of the disease. Many diseases, especially those caused by Protozoa, are now known to be carried from man to man or from animals to man or vice versa, by biting insects, which themselves are often necessary for some part of the developmental cycle of the disease-producing organism. Thus Malaria, which causes well over a million deaths per annum in India alone, is due to at least three closely-allied protozoal parasites (see p. 88), which require, in order to complete their development or lifecycle, to pass part of it in certain mosquitoes by whose bite the disease is communicated to man.

Sleeping Sickness, now spreading and causing such havoc among the negro races of Africa, is caused by a flagellated protozoon known as Trypanosoma gambiense (see p. 85), which is carried by a biting fly called Glossina palpalis and allied species; whilst a similar trypanosome, T. brucei, which causes Nagana or tse-tse fly disease, and works havoc among horses and cattle in certain parts of Africa, is carried by Glossina morsitans, the tse-tse fly. Numerous other diseases among warm-blooded animals which are caused by other trypanosomes are spread by biting insects, usually a fly, but sometimes a flea or a louse, as in the case of the rat trypanosome ( $T$. lewisi), or by a leech in the case of fishes. 
Many of the diseases caused by spirochaetes, an important group of pathogenic organisms the place of which in the scale of classification is still somewhat doubtful, are carried by biting ticks. Thus African Relapsing or Tick-fever, due to the Spirochaeta duttoni, is carried by the tick, Ornithodorus moubata; and numerous spirochaete infections of the lower animals, for example among fowls, are also carried by ticks.

One of the best known and most important of insect-carried diseases is Bubonic Plague, which is transmitted from its usual victim the rat, to man by the bite of the rat-flea, which, when its host the rat dies, migrates from the dead body and, if it cannot find another rat on which to feed, will attack and infect man. The plague bacillus can be seen microscopically in the rat-flea's stomach, in which it may be found up to the number of some five thousand or more.

Anthrax may be carried from sheep to sheep by the louse; Yellow Fever, caused by a filter-passing organism, is inoculated into man by the Stegomyia mosquito, and Typhus Fever, also due to a filter-passer, is believed to be carried by the bodylouse. Many other instances of insect-borne disease might be given, but it will suffice to mention, along with the above where biting insects are the carriers, the case of insects, especially flies, which carry disease-producing germs upon their feet or wings or proboscis, or especially in their alimentary canal, and so contaminate food or dishes and transmit infection to man. When the breeding- and feeding-places of flies, e.g. the ordinary domestic fly, are considered, the marvel is that more diseases are not so carried. Summer diarrhoea of infants, typhoid fever, dysentery, cholera, and similar diseases, and perhaps also tuberculosis, are from recent investigation now regarded as being probably extensively carried and distributed by common house and other flies, and hence all food should be carefully protected from them.

Food may be contaminated with pathogenic organisms in an enormous number of ways. The animal or vegetable from which the food is derived may be itself diseased. For example, some epidemics of meat-poisoning are due to the presence of certain bacteria belonging to the Coli-Typhoid group, e.g. B. enteritidis of Gaertner and its close relatives, B. paratyphosus and others. Anthrax may be communicated to those working with the carcases of sheep, cattle, etc., which have died from the disease, butchers, tanners, dock-porters and wool-sorters being among those most liable to suffer from the infection.

By far the most important infection, however, in this country which is extensively spread from diseased animals to man, is Tuberculosis. In this connection the actual diseased tissues 
of slaughtered animals play a much less important part than the product of the living animal-milk. An enormous amount of tuberculosis, especially among young children, is directly traceable to this cause; and "clean milk" or even comparatively clean milk is still practically an unknown commodity among us. In fact, until the public has become sufficiently educated to recognise its own peril from the contaminated and often filthy milk at present so commonly purveyed for its consumption, and until it demands from its legislators proper and sufficient safeguards-thorough cleanliness and sanitation in byre and cowshed, in dairy and milk-depôt-as long as tuberculosis is not ruthlessly stamped out from among our cattle, so long will the public be liable to preventable disease and death. Something is being done in this direction in some parts of the country, but far more drastic powers are required by our public health authorities, and far more thorough methods of inspection of farms and dairies is necessary. Far more thorough bacteriological examination of the milk itself, especially by means of animal inoculation, is essential, and it is no exaggeration to say that, in many of our towns where such examination is more or less thoroughly carried out, some eight or ten per cent. or more of the samples examined may be proved to be tuberculous. ${ }^{1}$ Mere inspection of the cows themselves is not sufficient, as an animal may appear healthy and yet be tuberculous and spreading the disease far and wide in its milk. The tuberculin test must also be systematically carried out by experts - as there are many fallacies and pitfalls in its use by the inexperienced.

What is known as "surgical tuberculosis," i.e. tuberculosis of bones and joints and glands, is mostly due to tubercle bacilli derived from milk. The infant and child mortality in this country from such infection is appalling; the death-rate in Edinburgh and Glasgow being, in Europe, second only to that in Budapest. In the surgical wards of the Royal Hospital for Sick Children, Edinburgh, operations for tuberculosis constitute some 50 per cent. of all operations done; whilst in the postmortem room, in above 30 per cent. of a consecutive series of over 600 autopsies performed by the writer in the past four years, death was directly due to the tubercle bacillus; and important experimental work done by the surgeons of that institution has proved that from 60 to 90 per cent. of all the

1 Dr. James Miller, in the Edinburgh Medical Journal for Feb. 1914, in a paper on "The Prevalence of Living Tubercle Bacilli in Edinburgh Milk," gives the results of an investigation in which he proved that 13 per cent. of samples bought from Edinburgh dairies contained living tubercle bacilli capable of producing tbe disease. 
cases of surgical tuberculosis in the children treated are due to infection with the bovine bacillus.

Products such as butter, ${ }^{1}$ cream and cheese, if made from tuberculous milk, can also spread the disease ; whilst diphtheria and scarlet fever and many forms of diarrhoea, are commonly spread in epidemic form by milk contaminated by the dairy workers, and possibly sometimes from the cattle themselves. Similarly, typhoid fever and cholera may be spread by milk, and are often traceable to the use of contaminated water in washing the dairy utensils and cans. Foot-and-mouth disease can also be communicated from cattle to man by milk and its products. Malta, Rock, or Mediterranean fever, a disease which was formerly very prevalent among our soldiers and sailors stationed in the Mediterranean, but which has been largely stamped out since its etiology has become known, is chiefly carried by the milk of goats, which suffer from this disease.

Milk which contains visible filth and sediment usually contains the actual faecal excrement of cattle, and enormous numbers of bacteria, some of which, e.g. certain of the streptococci, are pathogenic. Most of the bacteria present, however, are usually those of putrefaction, and much of the milk at present distributed in large cities is really in an advanced stage of bacterial decomposition.

Some idea of the extent of bacterial infection of milk may be gathered from the following tables, taken from Jordan's Bacteriology, the figures given being the number of organisms per cubic centimetre. ${ }^{2}$

Milk Collected with Great Care.

\begin{tabular}{|c|c|c|c|c|c|}
\hline & \multicolumn{4}{|c|}{ KEPT AT } \\
\hline & & $4^{\circ} \mathrm{C}$. & $6^{\circ} \mathrm{C}$. & $13^{\circ} \mathrm{C}$ & $20^{\circ} \mathrm{C}$. \\
\hline $24 \mathrm{hrs}$. & · & 2,500 & 3,100 & $\begin{array}{r}18,800 \\
\end{array}$ & 450,000 \\
\hline $\begin{array}{l}48 \mathrm{hrs} . \\
96 \mathrm{hrs} \text {. }\end{array}$ & : & $\begin{array}{r}3,600 \\
\end{array}$ & $\begin{array}{r}12,000 \\
1480,000\end{array}$ & $3,400,000$ & ... \\
\hline $168 \mathrm{hrs}$. & . & $4,209,000$ & $80,000,000$ & $\ldots$ & $\ldots$ \\
\hline
\end{tabular}

1 In a recent investigation (Lafar: Handbuch der technischen Mykologic) 727 samples of butter were investigated and tubercle bacilli found in 88 samples, or about 12 per cent.

2 One fluid ounce equals $28 \cdot 42$ cubic centimetres. One cubic centimetre therefore equals roughly about a thirtieth part of an ounce. To estimate the number of bacteria in a teaspoonful of milk, the above figures would require to be multiplied a bout three and a half times. 
Ordinary Mirk.

\begin{tabular}{|c|c|c|c|c|c|}
\hline & & \multicolumn{4}{|c|}{ KEPT AT } \\
\hline & & $4^{\circ} \mathrm{C}$ & $6^{\circ} \mathrm{C}$ & $13^{\circ} \mathrm{C}$ & $20^{\circ} \mathrm{C}$. \\
\hline $\begin{array}{l}24 \mathrm{hrs} . \\
48 \mathrm{hrs} . \\
96 \mathrm{hrs} . \\
168 \mathrm{hrs} .\end{array}$ & $\dot{.}$ & $\begin{array}{r}38,000 \\
56,000 \\
4,300,000 \\
38,000,000\end{array}$ & $\begin{array}{r}42,000 \\
360,000 \\
12,200,000 \\
300,000,000\end{array}$ & $\begin{array}{c}187,000 \\
38,000,000 \\
\ldots \\
\ldots\end{array}$ & $\begin{array}{c}4,000,000 \\
\ldots \\
\ldots \\
\ldots\end{array}$ \\
\hline
\end{tabular}

If milk is obtained with strict aseptio precautions, it may contain only a fow hundred organisms per centimetre. If less carefully collected, several thousand are present, and if carelessly drawn, some 30,000 to 100,000 bacteria per c.c. are found in the freshly-drawn milk, these large numbers being introduced into the milk from the skin of the cow, usually contaminated with faecal excrement, from the hands of the milker, and from dirty water used in cleaning the milking pails and pitchers. Dairy farmers and milkers as well as the middle-men and distributors and the general public must all be educated in these matters. There is at present almost incredible ignorance and carelessness, especially among the smaller dealers. For example, the writer recently heard of a dairy farm worker whose duty it was to take the milk cans to and from the local railway station, washing out some of his empty cans with the station lavatory brush! Cases of undiagnosed diphtheria and scarlet fever and human tuberculosis among those who handle the milk are frequent centres of epidemics of these diseases. Milk is one of the most suitable culture-media for bacteria, and therefore the question of cold storage is one of great importance. Bottled milk, if the bottles are really clean, is usually much more cleanly than ordinary dipped milk, and may contain an average of less than half a million organisms per c.c. as against four to eight or ten millions, which are quite common figures in the case of the latter. In some towns, in summer weather, seventy or eighty millions of bacteria may be found! In America, where the matter of clean milk is receiving more attention than in this country, the Philadelphia Milk Commission fixed the standard of certified clean milk at not more than 10,000 per c.c., New York at 30,000 , whilst other towns have a standard varying up to half a millionthough with proper precautions the more exacting standard can be attained with little difficulty. In this country very radical reform of the milk-supply is urgently required, and, 
by the resulting diminished sickness and death-rate, would rapidly repay any expense entailed.

Some diseases are more or less communicated from individual to individual by direct contact. The venereal diseases now occupying so much attention, are almost exclusively so communicated, though dirty towels and dishes are by no means infrequently another method of spread; whilst tobacco-pipes and glass-blowers' tubes are also well-recognised means of their carriage to innocent persons. Diphtheria and pulmonary tuberculosis, influenza and common colds and many other infective diseases may be communicated by kissing, or by breathing the fine spray of mucus or saliva ejected by the patient on coughing or sneezing. A peculiarly fatal form of plague, known as plague-pneumonia, is similiarly distributed. Again, some diseases, such as scarlet fever and smallpox, can be transmitted by articles which have been in contact with the patient, such as dishes, clothing, bedding, books, etc. Typhoid fever is spread by bacteria in the stools, urine, and other discharges which may lead to contamination of food, water-supplies, and, as is well known, shell-fish which grow near sewage-effluents.

One public health problem which is only beginning to receive the attention it deserves, is what is called the "Carrier Question." Many persons who have suffered from, say, typhoid fever or diphtheria, continue during convalescence, and even for months and in some cases many years afterwards, to harbour the causal organisms of these diseases in their bodies, and act as distributing centres to which many epidemics have been traced. Even apparently healthy persons, who have not as far as is known suffered from a definite attack of these diseases, may similiarly have these organisms in their bodies and may act as "carriers." Outbreaks of typhoid and of diphtheria, especially in institutions such as asylums, hospitals, and schools, have of late years frequently been traced to infection from such "carriers." Domestic animals may act in a similar way, and cases, for example, of diphtheria in the human subject have been traced to infection from the domestic cat.

In order to preserve the health of the individual, it is therefore obvious that two sets of measures must be brought into play. The resisting powers must be maintained in as high a state of efficiency as possible. Good housing, fresh air, light and exercise and sleep, good and sufficient food and clothing, are important factors from this point of view. Secondly, there is the avoidance of undue exposure to infection-a clean food-, water-, and milk-supply, the isolation of infectious cases, and the disinfection of their excreta, etc., and the destruction of dis- 
eased animals, especially tuberculous cattle, suggest themselves as obvious precautions; whilst the reduction of germ-laden dust on oúr roads and in our cities is a reform urgently required; such dust acting, not only as a carrier of disease, but by its entrance into the lungs damaging the tissues and preparing the way for the action of the accompanying bacteria.

For the methods by which organisms spread and cause disease within the body, reference must be made to larger works. It is sufficient here to mention that some bacteria, such as the diphtheria bacillus, usually remain localised in the throat or neighbouring parts, their toxins alone being carried into the tissues of the body by the lymph-and blood-streams. Similarly, tetanus bacilli remain localised in some wound, often quite small, and manufacture their toxins, which in the same way pass in and poison the body tissues. Again, some organisms, e.g. the cholera germ, remain localised in the intestine, whilst others, such as the typhoid bacilli, are carried far and wide throughout the body. Some organisms which are usually described as causing wound infection may produce a trivial local inflammation, serious spreading inflammatory conditions such as erysipelas, abscesses and the like, or general infection of the whole body, as in septicaemias and pyaemias. The severity of the disease depends on the virulence, number, method and site of introduction of the causal organism, the presence of other bacteria, the relative susceptibility or otherwise of the tissues and also the presence of other diseased conditions in the body, as indicated in our chapter on Immunity.

Before passing to the consideration of the organisms which produce disease, the following terms may be briefly defined.

Inflammation : a very indefinite term, which embraces the "series of reactions in the tissues which follows irritation or injury, and which has for its special purpose the prevention or repair of damage," bacteria and their toxins being the commonest and most important causal agents. Inflammation may be acute, subacute, or chronic, according to the time it lasts.

Suppuration: is a form of inflammation usually caused by organisms which possess the property of softening and digesting the tissue by means of digestive ferments, the pus or "matter" so formed consisting of leucocytes which pass in to attack the organisms, the softened and liquefied tissues of the part, and the bacteria themselves and their toxins. Suppuration may occur on a surface as a purulent catarrhal inflammation, or may be localised in the substance of a tissue as an abscess. It may spread through the tissues as a purulent infiltration, e.g. in erysipelas, or it may occur in one of the serous cavities of the body such as the peritoneal lining of the abdomen, 
in the pleural sacs around the lungs, the pericardial sac in which the heart lies, in the meninges around the brain, etc., or in a joint or similar cavity.

Toxaemia : is a condition in which the toxins or poisons produced by organisms or other agents pass into the circulating blood, and so come to act on all the tissues of the body, sometimes injuring them all, sometimes picking out some special tissue, as in the case of tetanus toxin and nervous tissue in Lockjaw.

Septicaemia : is where the disease-producing organisms themselves pass into the blood, and in its severer forms (in anthrax, plague-septicaemia, etc.), proliferate there in enormous numbers and are therefore found throughout all the tissues of the body.

Septicaemia and toxaemia are often combined in the same disease.

Pyaemia: when suppurative inflammation attacks a vein, the blood within it may become thrombosed or solidified. The organism may then infect and cause softening of this thrombus or solidified blood, which may be carried along the veins and be distributed throughout the body in the circulating blood. Portions of the softened and infected material so carried may settle down in any part of the body and cause the formation of abscesses, e.g. in the lungs or other organs, joints or bones.

\section{CHAPTER VII}

\section{SOME OF THE COMMONER ORGANISMS WHIOH PRODUCE DISEASE}

\section{Group of Organisms causing Wound-Infection, Inflamma- tion, and Suppuration}

As explained above, the same organism may in one instance produce suppuration, localised as abcesses, boils, or carbuncles ; in another a spreading inflammation such as erysipelas and other forms of cellulitis (inflammation of the cellular connective tissues, especially those of the skin ;) or again, a generalised infection such as a septicaemia or a pyaemia - the form of disease so produced depending upon the virulence, number, and method of introduction of the organisms into the body on the one hand, and upon the susceptibility or resistance of the tissues to the attack on the other.

Some of these organisms of wound-infection are very common 
and are found practically everywhere; others are less common, and some are rare.

Suppuration is common with the Staphylococci, Streptococci, and Pneumococci, the Pneumobacillus, B. coli, Gonococcus and Meningococcus, $M$. tetragenus, $B$. pyocyaneus, etc. ; and is not infrequent with $B$. typhosus, $B$. tuberculosis, $B$. mallei (the cause of glanders), and various Streptothriceae.

1. The Staphylococcus group.-The commonest and most important member of this group is Staphylococcus (or Micrococcus) pyogenes aureus, which is widely diffused in nature - practically everywhere-but especially on the skin and in the mouth, and in the dust of houses. It can therefore readily gain access to a wounded surface. It varies very much in virulence, and may cause anything from the most trivial to the most serious infections. It is the organism most often found in acute abscesses and boils and surface suppurations. One of the most severe infections which is specially liable to be caused by this organism, particularly in young subjects, is suppuration in or round the bones (suppurative periostitis and osteo-myelitis), which is often in its early stages wrongly diagnosed as rheumatic fever, a very unfortunate mistake, as the condition requires immediate surgical operation. This Staphylococcus is also one of the commonest causes of pyaemia, which used to be a terribly widespread disease in the old days, before antiseptic surgery was introduced, but which is now fortunately comparatively rare.

Microscopically, the organism is a small round coccus, less than a micromillimetre in diameter, growing in little masses or clusters resembling bunches of grapes, from which it gets its name "Staphylococcus" (see Frontispiece, fig. 1). It stains easily with the ordinary stains. In culture it produces a dull orange-coloured growth from which the descriptive name "aureus" is derived. It grows easily both at room- and at blood-temperature, on all ordinary culture-media, and produces liquefaction of gelatin. It is killed by an exposure of ten minutes to moist heat at $56^{\circ}$ or $58^{\circ} \mathrm{C}$.

Other members of this group of less importance are Staphylococcus pyogenes albus and citreus, giving a white and lemonyellow-coloured growth respectively. The former is very common in the skin, and the latter in the throat.

Many infections due to staphylococci do well with vaccinetherapy, proper surgical treatment being of course also employed.

2. The Streptococcus group.-The commonest pathogenic member of this group is the Streptococcus pyogenes. The Pneumococcus is now usually regarded as belonging to the streptococci. 
The Streptococcus rhermaticus is the probable cause of acute rheumatism. Other members of the group are of less importance. The Streptococcus pyogenes is a frequent cause of spreading inflammation of serous and mucous membranes, erysipelas, cellulitis, lymphangitis, ${ }^{1}$ and the like; also in localised'suppurations and abscesses-usually acute, but sometimes chronic. Pyaemias and septicaemias are often due to this streptococcus, puerperal fever being a serious septicaemic condition caused by infection of the womb after child-birth, most commonly by the Streptococcus pyogenes, either alone or with other organisms, especially $B$. coli. The Streptococcus is very frequently found in the throat as a complication of diphtheria and scarlet fever. Either alone or along with the Pneumococcus, it is a common cause of broncho-pneumonia especially after surgical operations on the mouth and neighbouring parts, and also in the case of children after measles and whooping-cough. It is a frequent cause of empyema or suppuration in the pleural cavity around the lung, especially in children.

Microscopically it is a coccus of about one micromillimetre in diameter, with a tendency to form shorter or longer chains, whence its name, though it is also often found in pairs (see Frontispiece, fig. 4). It is easily stained. On culture, it is much more delicate than the staphylococci, and tends to die out somewhat rapidly. It forms small, rounded, translucent colonies on a solid medium, and it does not liquefy gelatin.

The Streptococcus rheumaticus in shape and size closely resembles the above, but it is a much hardier and more resistent organism. It has been obtained from rheumatic sore throats, and from the various lesions produced by rheumatism in the heart, joints, serous membranes, etc. All the typical lesions of rheumatism have been reproduced by the inoculation of rabbits with this organism-even chorea or "St. Vitus' dance," which in its ordinary form is a definitely rheumatic manifestation. Some bacteriologists, however, still deny that this organism is the cause of rheumatism, and speculate as to the possibility of some filter-passing microbe being the causal agent, of which there is at present certainly no proof.

The Pneumococcus is one of the commonest pathogenic organisms, and may produce, not only acute lobar or croupous pneumonia, of which it is the specific cause, but also inflammations and abscesses in any part of the body. In a more or less non-virulent form it is found in practically every mouth

1 The inflamed lymphatic channels may show as red lines, for example passing up the skin of the arm when some wound, perhaps on a finger, is infected. 
and throat; and if ordinary saliva is injected into a rabbit, the animal usually dies rapidly of a pneumococcal septicaemia, showing that this organism can at any time, under suitable circumstances, acquire special virulence and activity and become pathogenic if the patient's vitality is lowered. It is a very frequent cause of colds and sore throats. It may co-operate along with numerous other organisms, and may be found in influenzal attacks, broncho-pneumonia, and in secondary pneumonias occurring during and after the acute infective fevers. When virulent it may be spread by contagion and cause epidemics of acute lobar pneumonia, bronchopneumonia, bronchitis, and sore throat; and, especially in enfeebled patients such as drunkards, and in young children, generalised infection is common. Any serous sac (pleurae, pericardium, peritoneum, meninges, joints, etc.), may be attacked, and middle ear disease is very often due to this organism, the infection taking place from the throat along the Eustachian tube, which is a small air-passage which connects the middle ear and throat.

Microscopically in its typical form it is shaped like the oldfashioned blood-letting lancet, or like the flame of a candle, and is usually found in pairs (hence, in addition to its commoner name of Pneumococcus, it is sometimes called Diplococcus lanceolatus or Diplococcus pneumoniae), or in short chains, from which another of its synonyms, Streptococcus pneumoniae, now in common use, is derived. The Pneumococcus, especially when in the blood or in a serous exudate, and in the sputum, usually possesses a well-marked capsule around it, which may be demonstrated by appropriate staining methods and gives it a characteristic appearance (see Frontispiece, fig. 2). When dogenerated, it loses its typical shape, and may become oval or even rounded in outline, in which case it is difficult to tell it from other forms of streptococci, the inoculation of a mouse or rabbit being the easiest test, as it then regains its typical shape and capsule.

On culture, its growth resembles that of the Streptococcus pyogenes. It is a delicate organism, requiring incubation at body temperature. It grows best on blood-serum or on media to which blood has been added. Cultures tend rapidly to lose their virulence and die out.

3. The Pneumobacillus is a member of the Coli-Typhoid group, and will be considered along with them (p. 70).

4. Micrococcus tetragenus, so named from being frequently found in groups of four, or tetrads as they are called (see Frontispiece, fig. 5), is occasionally found in abscesses, and may sometimes give rise to more serious general infection. 
5. The Gram-negative Group of Cocci.-The various cocci (Staphylo-, Strepto-, and Pneumo-cocci and M. tetragenus) mentioned above are all stained positively by a special differential stain known as Gram's method. There are also several very important cocei which do not stain by this method, and which are therefore known as the Gram-negative group. Of these the Gonococcus, the Meningococcus, and Micrococcus catarrhalis are the most important.

The Gonococcus, also known as the Micrococcus gonorrhoeae, is the cause, not only of the all too common venereal infection of both sexes from which it derives its name, but it may produce widespread and very intractable secondary infections of the bladder, uterus and its appendices, peritoneum, joints ("gonorrhoeal rheumatism"), and even ulcerative endocarditis or heart disease. It is found in the purulent discharge from gonorrhoea or gleet, and in gonorrhoeal conjunctivitis or inflammation of the surface of the eye and eyelids. The last-mentioned condition is unfortunately very common in newly-born infants who have been infected at birth from the passages of the mother, but it may also be found in children and older persons from the use of contaminated towels. Many of the cases of partial or complete blindness in our blind asylums are due to its ravages. Animals other than man are practically immune to its action.

Microscopically, it is found in the discharges-sometimes free, but most commonly intracellularly, i.e. within the phagocytic leucocytes and other cells (see Frontispiece, fig. 23). It is generally found in pairs, each coccus usually somewhat kidney-shaped, with the concavities towards each other. It stains readily with the basic aniline dyes, and, as above mentioned, it is Gram-negative.

It is a somewhat difficult organism to grow artificially. It requires special media-blood-serum, or better still, phosphateagar smeared with blood, kept at body-temperature. It dies off rapidly.

The Meningococcus or Micrococcus intracellularis meningitidis, is the cause of the deadly disease known as epidemic cerebro-spinal meningitis. Isolated or sporadic cases of this disease, which specially attacks children, are not uncommon, but as the name implies, it may occur in epidemics, and it sometimes even becomes pandemic, i.e. occurring in any country of the world. A few years ago such a pandemic occurred, causing many deaths in Europe, America and elsewhere, as many as eighty per cent. of the cases ending fatally. It is sometimes extraordinarily rapid in its action, death resulting in a few hours; but usually the disease lasts several days, 
weeks, or even months, chronic cases sometimes occurring and usually leading to mental impairment of the victim. The organism is harboured especially in the nose and throat of contacts, and may be communicated by such persons, who may themselves not exhibit signs of illness, to others, and cause the meningeal form of the disease, i.e. that in which the covering membranes of the brain and spinal cord are attacked.

Microscopically the organism occurs in the inflammatory,exudate over the brain and the spinal cord, and its presence may be demonstrated by withdrawing (by "lumbar puncture" as it is called) and examining a little of the cerebro-spinal fluid which bathes these organs and is usually increased in amount in this disease. In shape it closely resembles the Gonococcus, and like the latter, as its name implies, is usually found inside the cells of the exudate. It can be differentiated from the Gonococcus by cultural methods and by tests based on certain immunity reactions (see p. 49). Serum treatment, especially by the serum introduced by Flexner of New York, has done something to lower the case-mortality of this terrible disease, the serum being introduced directly into the spinal canal. A very closely allied organism, known as Still's Micrococcus of Posterior Basic Meningitis, can be differentiated from the Meningococcus only by careful and elaborate cultural and immunity tests.

The Micrococcus catarrhalis and certain closely allied organisms are common in the nose and throat, and are increased in many cases of catarrhal inflammation such as colds, sore throats, and bronchitis. Though not themselves highly pathogenic, they add their adverse influence in infection by other organisms such as Pneumococci, Streptococci, $B$. infuenzae, $B$. diphtheriae and others-mixed vaccines in such cases being sometimes very efficacious in bringing about a cure. The $M$. catarrhalis, unlike the Gonococcus and Meningococcus, grows easily upon ordinary media and at ordinary roomtemperature $\left(20^{\circ}\right.$ C.).

\section{Group of Organisms producing Specific Infective Fevers, etc.}

Micrococcus melitensis (Bacillus or Cocco-bacillus melitensis). - This organism is a very minute, slightly elongated Gram-negative cocco-bacillus (i.e. an organism coming between the cocci and bacilli as regards its shape), and is the cause of Malta, or as it is now preferably called, Mediterranean Fever, a long-continued disease characterised by intermittent or undulating waves of temperature, with joint-pains, emaciation, 
sweating, etc., prevalent, as the name implies, in the Mediterranean area, but also occurring in South Africa, America, India, the Far East, and elsewhere. For many years past, the garrison of Malta, as well as the natives of that island, had been subject to this disease, some 650 of our sailors and soldiers falling ill with it annually. The case-mortality of the disease is low-from two to three per cent.-but, as each patient had to stay on an average 120 days in hospital, giving roughly a total of some 80,000 days of illness per annum, and as most of the convalescents had to be invalided home, great inconvenience and expense was entailed. In 1904, a small Investigation Commission was sent to Malta by the Royal Society at the request of the Government, and it was discovered that the organism, which had previously been identified as the cause of the disease in the human subject, was harboured by the goats of the island, about 50 per cent being affected, and was communicated to man chiefly in their milk, the organism being found in the milk of 10 per cent. of these animals. This important fact was elucidated by careful research, and especially by the artificial inoculation of animals, and led to goats' milk being eliminated as an article of diet among the garrison. This was at once followed by a drop in the number of cases to a tenth of what they had formerly amounted to, and now the disease is practically stamped out among our soldiers and sailors in the island-a triumph of modern scientific methods (see Fig. 15).

The organism is present in the blood and internal organs, especially the spleen, and is found in the urine and other excretions. It stains, sometimes rather faintly, with the ordinary dyes, and grows easily, though somewhat slowly, on the usual laboratory media, with the production of rounded colonies, more or less translucent and colourless at first, later becoming more opaque and of a yellowish-brown or orange tint. Gelatin is not liquefied. The diagnosis of the disease can be confirmed, not only by obtaining the organism itself from the cases, but also by the agglutination reaction (see p. 49), antibodies in the patient's blood-serum, even when much diluted, causing clumping together of the organism.

Bacillus pestis.-The history of Plague would occupy a large volume. As is well known, epidemics of this disease ravaged Europe in the Middle Ages, Great Britain suffering from it as the Black Death in the fourteenth, and as the Great Plague of London in theseventeenth centuries, numerous lesser epidemics having occurred, some of them, e.g. in Glasgow, Ipswich and elsewhere, within the last few years, but, thanks 
to our modern knowledge of the methods of spread of the disease, successfully stamped out bythe public health authorities before becoming general. The disease has sometimes become world-wide or pandemic, and it is still endemic, i.e. always present, in many parts of Asia. It is an acute, infective, inoculable disease, and in some of its forms, e.g. plague-pneumonia (see p. 55) also highly contagious. It is primarily a disease of certain of the lower animals, especially the rat, which is the
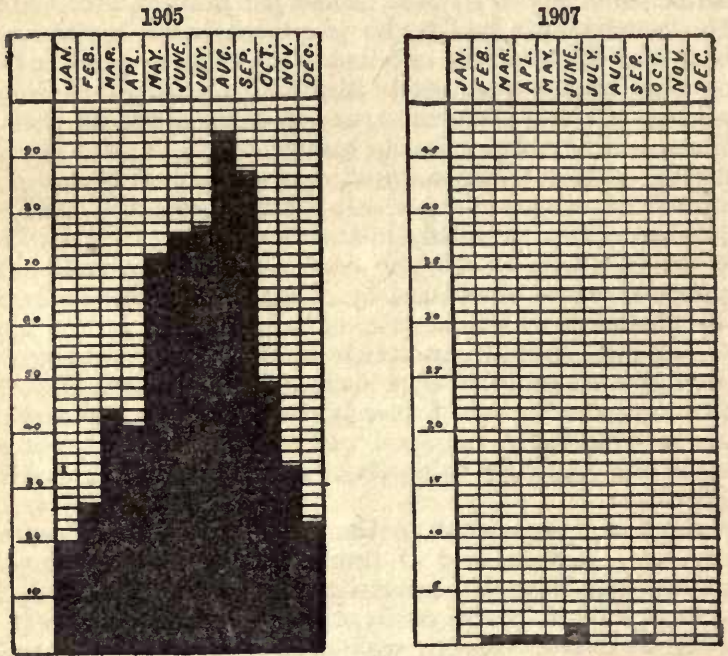

FIG. 15.-Diagram showing the number of cases of Malta Fever among our soldiers in 1905 and 1907 . The offcial order forbidding the supply of goat's milk to the garrison was issued on July 1st, 1906.

main source of infection ; but mice, rabbits, and hares, squirrels, ferrets, marmots and bandicoots, cats, monkeys, and other animals may also contract the disease and act as reservoirs of infection. From these it may be communicated to man by the bite of fleas and possibly other parasites, a rat-flea being the most important transmitting agent.

Various clinical forms of the disease are recognised, e.g. the Bubonic, characterised by glandular swellings ; the Pneumonic where the lungs are specially attacked; and the Septicaemic, where the blood is infected. The epidemics in China in 1910-11, and in Suffolk in 1910, were of the highly fatal pneumonic type. 
The experimental evidence of the carriage of plague by fleas is extremely interesting. Guinea-pigs and other susceptible animals, if placed in fine gauze- or muslin-protected cages in a plague-infected house or near infected animals, do not catch the infection, whilst similar animals in unprotected cages are infected. Another method by which the caged animals can be protected is to place sticky fly-paper on the ground or platform round the cages for a breadth greater than a flea can jump.

The organism is a small, somewhat oval-oblong or punt-shaped bacillus, with rounded ends which show characteristic bi-polar staining (see Frontispiece, fig. 11). It is non-motile, does not form spores, and is Gram-negative. It may be found singly or in pairs or even in chains, especially if growing in a fluid. It grows easily in culture-best at body-temperature, but also at ordinary room-temperature. It is very resistant to cold, and is not killed by prolonged freezing, but is easily killed by heat and antiseptics.

Haffkine's Plague Prophylactic Vaccine is prepared from a peptone-broth culture on the surface of which a layer of melted butter or fat is allowed to float. From the under surface of this the organism grows down into the fluid in stalactite-like processes which break off easily on shaking and fall to the bottom. After a sufficient period of growth, the broth culture is killed by heat, standardised, and used in small quantities for injection as a preventive vaccine (see p. 47). Various sera have also been tried for the treatment of plague, but with as yet comparatively little success.

Several bacilli closely allied to $B$. pestis produce plague-like diseases in some of the lower animals.

B. influenzae is a very minute, non-motile, Gram-negative bacillus which is believed by many to be the cause of Influenza in its protean forms. The term "Influenza" is often somewhat loosely used for any highly infectious cold and other ailments, but in the specific disease this bacillus is found, though often along with other pathogenic bacteria, e.g. the Pneumococcus. It may be found in enormous numbers in the discharge from the nose, and in the sputum in bronchitic and pneumonic cases, and it may also be found in the middle ear, the meninges, and elsewhere.

On culture, it will grow only if haemoglobin, the red colouring matter of the blood, is added to the medium. It forms minute, rounded, transparent colonies, incubation at body temperature being necessary for its growth. It rapidly dies out. It is probably a member of a somewhat large and at present incompletely differentiated group of closely related organisms, some 
of which may cause a very fatal form of meningitis so-callec "leptothrix infection"). The influenza bacillus is extremely delicate, and is probably transmitted from case to case mostly by the inhalation of the fine spray produced on coughing and sneezing, or even speaking. The Bordet-Gengou Bacillus now believed to be the cause of Whooping-Cough, is ar organism of somewhat similar type to the influenza bacillus.

B. anthracis.-Anthrax, Splenic Fever, or Splenic Apo plexy, so called from the enlargement of the spleen, is importan as being the first disease in which the specific activity of , bacterium was studied and demonstrated. It is a very fata septicaemic disease in cattle, whilst sheep, horses, swine, goats deer, and other animals are less frequently attacked. Labora tory animals such as guinea-pigs, rabbits, and mice are very sus ceptible. From any of these it can be communicated to man who is usually infected by handling the carcases or their pro ducts, such as blood, flesh, hides, hair, wool, etc. The bacillu: is of large size, 5 to $12 \mu$ or even more in length and $1.25 \mu$ is breadth. It is non-motile, with somewhat square or eves slightly concave ends, and in culture tends to form long thread or chains, and is strongly Gram-positive (see Frontispiece fig. 9). Very resistant oval spores are formed by this bacillu (see Fig. 10), and these can retain their vitality for months o even years. Within the living body spores are not usuall formed, but they occur very readily after death. As the diseas is a septicæmia, the organism is spread throughout the whol blood and tissues of the animal.

In man the commonest clinical forms of the infection are : (1 Malignant Pustule of the skin, commencing as a red pimpl which soon becomes a vesicle or little bleb, and then a pustule This may dry up and form a dark, brownish-black scab, fron which the name Anthrax (Latin : anthrax, black) is derived There is usually intense swelling of the surrounding parts (2) Wool-Sorters' Disease, due to inhalation into the wind pipe and larger air-passages of particles of infected hair o wool. (3) Septicaemic Form, resembling that seen in cattle

The bacillus grows easily in all the ordinary culture-media giving a growth with a very characteristic, wavy, wisp-like out line if on the surface; and, if grown in the substance of medium such as gelatin or agar, often producing a fir-tree like branching or "spiking" as it is called. Gelatin is slowl liquefied

Bacillus diphtheriae.-This very important organism, th cause of Diphtheria, belongs to a large group of which it is 
practically the only pathogenic member-the others being usually termed pseudo-diphtheria, diphtheroid, or diphtherialike bacilli. From these it can be distinguished by various more or less refined staining and cultural methods, and also by inoculation into animals. Infection may be communicated directly from infected persons, or from animals such as the cat, or may be carried by articles contaminated by sputum and secretions, e.g. milk, dust of rooms, bedding and clothes, dishes, etc. The inhalation of cough-infected air is one of the most usual means of contracting the disease, which has naturally become more prevalent since the introduction of compulsory education. The site of infection is usually the throat and neighbouring parts, and it is specially dangerous when it spreads to the larynx. The nose, eyes, occasionally the genitals, and sometimes the skin, especially if already injured, may be affected. The bacillus, as explained in a previous chapter (p. 56), remains more or less localised in the lesion, whilst the toxins which it manufactures pass into and circulate throughout the body, sometimes causing serious damage to the heart, kidneys, nervous system, vessels and other tissues.

The typical local lesion, often well seen on the tonsil, is a dirty yellow patch of ulceration covered with a "false membrane" resembling wash-leather in colour and appearance, and due to necrosis (i.e. death) of the mucous membrane and other changes. This typical appearance is not always seen. The part affected may be out of sight, or it may be atypical-perhaps merely a reddening and swelling of the throat. Such cases can be diagnosed only by bacteriological methods, and this is also true of the "carrier-cases" already discussed on p. 55. Other organisms such as Pneumococci, Streptococci, M. catarrhalis, Staphylococci, Diphtheroid Bacilli, are usually found along with the Diphtheria Bacillus in increased numbers.

The bacillus varies greatly in size, small, medium and large forms being recognised. It is non-motile and Gram-negative. It is best examined when grown in a young serum culture, on which medium it grows very rapidly, outstripping most other organisms. Microscopic examination of such a culture usually shows a peculiar grouping of the bacilli, due to the method of division, and suggesting groups of spilt matches, or, as some of the books describe it, like Chinese letters. With special staining-methods, peculiar granule-like bodies may be demonstrated, which are of considerable importance as aids to the diagnosis (see Frontispiece, fig. 10). In doubtful cases, certain differential cultural tests, and the inoculation of a guinea-pig, usually with a small quantity of a broth culture which will also contain the free toxin manufactured by the bacilli, are neces- 
sary. Peculiar degeneration forms are often seen, both in films from the throat and from cultures, the most characteristic being an Indian-club-like swelling of one end of the bacillus (see Frontispiece, fig. 10). The bacillus is a very hardy one, and will live for a long period when dried. It does not, however, produce spores.

Diphtheria toxin and antitoxin.-The toxins of the diphtheria bacillus may be artificially prepared by filtering a broth culture, suitably grown, the resulting germ-free fluid containing the highly-poisonous products of the bacillus. This fluid ${ }^{1}$ may be used for experimental work upon animals, for example for the production of active immunity in horses (see p. 48), the resulting serum being prepared in large quantities commercially and sold for therapeutic and prophylactic use as "Anti-diphtheritic serum" or "Antitoxin." It must be used as early as possible in the disease, and in sufficient quantity, and, especially in serious cases, must be injected frequently. Since its introduction, there has been a remarkable diminution in the death-rate from diphtheria. There is usually rapid improvement of the case-unless the treatment has been commenced too late-with casting off of the false membrane, etc. Local antiseptic treatment of the throat must also be thoroughly carried out. In cases where the bacillus persists in the throat during or after convalescence, vaccine-treatment, or this combined with the use of the antitoxin, may bring about its disappearance, though in some cases it is extremely persistent. Another point of importance is that certain paralytic lesions may follow diphtheria, due to the poisonous action of the toxins on the nervous system. These are not always prevented by the use of antitoxin. Many more cases now survive the disease because of antitoxin treatment, and any apparent increase in the number of such cases of post-diphtheritic paralysis is due to the fact that in the old days such patients would have died instead of surviving and showing this phenomenon.

Bacillus mallei.-Glanders or Farcy is a disease especially of horses, mules, and donkeys, and is transmissible to certain other animals and to man, and also to laboratory animals, especially guinea-pigs. It may be acute or chronic, and in horses and other equines, the disease usually starts with inflammation and ulceration of the mucous membrane of the nose. From this position it tends to spread along the lymphatic channels and to the lymphatic glands of the neck, producing

1 A very virulent strain of $B$. diphtheriae may produce enough toxin in a single cubic centimetre of the fluid to kill off a thousand guinea-pigs. 
cord-like and knot-like swellings, called by veterinary surgeons "farcy-pipes" and "farcy-buds." These are liable to a cheeselike form of necrosis called caseation, and may break down, ulcerate, and discharge purulent lymph containing the organism. Similar nodules-"glanders-" or "farcy-tubercles" - may be produced in the lungs, and are firm and more or less fibrous, with a tendency to caseation and softening.

In man, the infection, which usually attacks those who have charge of and are in contact with horses, may also follow an acute or a chronic course. Inoculation may occur in the nose from breathing air contaminated by the sneezing of an infected animal, or on the hands or face through a wound. The chronic form resembles the farcy of horses, and spreads especially along the lymphatics. The acute form in man is a very serious and often rapidly fatal disease, resembling pyaemia, with a multiple pustular eruption, especially on the face and arms, resembling confluent smallpox, together with intense fever and multiple abscesses in the skin, muscles, lungs, and other organs. Laboratory workers have sometimes fallen victims to this disease whilst investigating the condition.

Microscopically, B. mallei is a small, slender, rod-shaped bacillus, often very slightly curved. It is non-motile, Gramnegative, rather difficult to stain with ordinary dyes, and does not form spores. It is easily cultivated, and grows best on glycerinated potato, upon which it gives a characteristic pale brown, syrupy, or honey-like growth. It is easily killed by heat and antiseptics.

Diagrosis of the disease in horses in pre-bacteriological days used to be made by putting along with the suspected animal a donkey, which is very liable to the acuter forms of the disease. Now, diagnosis is made by the bacteriological examination of the discharge, by the inoculation of a guinea-pig, and by the mallein and other serological tests. The mallein test, which consists of the injection of a concentrated glycerinbroth culture prepared in a similar manner to tuberculin (see p. 81), produces in an animal suffering from the disease a febrile reaction and marked local pain and swelling.

Vibrio cholerae.-Cholera, the specific infective disease produced by this organism, is characterised by intense diarrhoea and general toxic symptoms such as muscular cramps, heartweakness, and emaciation. The infection is usually carried by drinking water contaminated by infective excrement from the bowels, and by the eating of raw vegetables, salads, and other foods similarly contaminated, or which have been washed in infected water. Flies may carry the infection after alighting 
on excrement from cholera cases, and human "carriers," either contacts or convalescents, are also centres of infection.

In the cholera patient, the presence of the organism is restricted to the intestinal canal, especially the small intestine, from which the absorption of toxins takes place. Extensive damage is produced in the mucous membrane of the bowel, with congestion, necrosis, and ulceration, the contents being fluid, stinking, and blood-stained, with shreds of mucus, lymph, and cells, constituting the "rice-water" stools so characteristic of the disease. The organism swarms in these, often in enormous numbers.

Microscopically, it is a small curved organism or vibrio, often called, after its discoverer, Koch's Comma Bacillus (see Frontispiece, fig. 13). It is very actively motile, and possesses a long, delicate, vibratile flagellum at one end (see Fig. 9, a). It may sometimes form spiral chains, and involution or degeneration forms are common. It is Gram-negative.

It is easily cultivated, growing readily and rapidly on ordinary media, especially if incubated at body-temperature with an abundant supply of oxygen. It forms a scum on the surface of liquid media, and liquefies gelatin, producing in a stab culture a characteristic bubble or bell-shaped area of liquefaction, which later becomes more funnel-shaped. In peptonewater or peptone-broth it produces indole and nitrite from the splitting of the protein - a red reaction, called "CholeraRed," being obtained with suitable chemical tests.

In culture and in ordinary water it may remain alive for long periods, but is easily killed by antiseptics and by heat and drying. It is important to remember its tendency to grow at the surface near the air, as, in examining a water-supply, the specimen is best taken from the surface. For the diagnosis of the disease, in addition to the finding of the vibrio in the intestinal discharges and its characters on culture, the agglutination test (see p. 49) and bacteriolytic (Pfeiffer's) reaction (see p. 49) are of great importance. Serum-treatment has not yet met with much success, but prophylactic as well as therapeutic vaccination are now widely practised.

Many other vibrios, mostly non-pathogenic, though some may cause disease in animals, are found, especially in the water of certain rivers.

Coli-Typhoid Group.-This is a very important and highly complex group, which contains many actively pathogenic and some comparatively harmless members. Many of them are more or less intermediate between saprophytes living on dead organic matter, and parasites living on or in living tissues, 
ready to take on a pathogenic character. All are more or less similar in their morphology. If well grown they are usually short, plump, straight, Gram-negative bacilli with rounded ends, some being motile, others not. None of them liquefies gelatin, and none forms spores. Most of them grow easily on all the ordinary media, and differ widely in their power of fermenting various sugars and other substances, a property made use of in differentiating them one from another. Each is agglutinated in high dilution by its homologous serum, i.e. the serum of an animal or patient infected with the specific organism to be tested-a fact which constitutes one of the most delicate means of differentiating them one from another.

The name Typhaceae has been applied by Löfler to the whole Coli-Typhoid group, and they may be divided roughly into three chief sub-groups :

1. The Coleae, including $B$. coli and its relatives and certain closely allied Capsulated Bacilli.

2. The Iosarceae or Meat-Poisoning Group.

3. The Typheae, including B.typhosus, thedysentery bacilli,etc.

Enormous numbers of differential tests, especially the effects of their fermentation activities upon various special culturemedia, have been introduced for isolating and determining the identity of these organisms. Speaking generally, the first of these sub-groups contains members which are very active fermenting agents, the third are much less active, whilst the second group is intermediate in its activity; but for details, reference must be made to larger works on bacteriology, complicated tables of these reactions having been drawn up for workers specially interested in this great group of organisms. Only a few more important members need be mentioned here.

Coleae : Bacillus coli is one of the most widely diffused organisms in nature. It is found in enormous numbers in the intestine of man and most other animals, and it is therefore found in water, soil, dust, or wherever faecal contamination, of which it may be taken as an index, is to be found. In its usual form in the intestine it may be regarded as a harmless organism combining the rôles of saprophyte and semi-parasite, and indeed, aiding in the breaking up of food in the large intestine, in which, especially in the caecum, bacterial digestion is now recognised as playing an important part in the animal economy. There are, of course, many other varieties of organisms also present in the bowel-Streptococci, Staphylococci, Coliform Bacilli, and numerous other aerobic and anaerobic bacteria, which also take part in this process, and which may, along with other organisms not normally inhabitants of the bowel, under 
abnormal circumstances come to produce disease. Bacillus coli, however, is usually by far the most numerous of these. If, from damage to the wall of the intestine, either from actual wounds or from disease, $B$. coli is enabled to make its way into the tissues, it may give rise to serious disease, abscesses, peritonitis, appendicitis, or the like being very commonly due to this organism, either alone or in company with other bacteria. Primary infection in these parts by the latter, e.g. by Streptoor Pneumococci, etc., is frequently complicated by the secondary appearance of $B$. coli in the lesion, and the latter organism may then outgrow and obscure the original cause. Infection of the urinary tract with $B$. coli is very common, especially in women and children; whilst this organism, as previously mentioned (p. 5S), may also ficly a part in ordinary wound infection. Certain diseases of plants are believed to be caused by an organısm apparently identical with $B$. coli.

$B$. coli is usually, though not under all circumstances, a motile organism; whilst certain very closely allied bacilli, known as the Capsulated Group, are non-motile, and, as their name implies, possess a capsule around them. Some of these are very common in sour milk, e.g. B. lactis aerogenes, which is usually nonpathogenic. Bacillus pneumoniae or Friedländer's Pneumobacillus, is very frequently found in nasal catarrh, sore throats, bronchitis cases, and the like. It may also be found in the lungs, in empyema pus, and in abscesses. Although it may itself cause disease, it is more usually associated with or follows invasion by other pathogenic bacteria, such as Pneumo- or Streptococci. It causes a rapidly fatal septicaemia if inoculated into mice; and on culture, it often gives a peculiar translucent slimy or mucous growth which is more or less characteristic.

Iosarceae : B. enteritidis of Gaertner and various Paratyphoid bacilli and their relatives are of great importance in connection with certain cases and epidemics of food-poisoning which have already been discussed under that heading (pp. 4l, 51).

Typheae: B. Typhosus, the specific cause of Typhoid or Fnteric Fever, is a very important member of the Coli-Typhoid group. It is actively motile, grows easily on most culturemedia, and is differentiated by numerous complicated special cultural and other tests, of which the agglutination reaction, often referred to in this connection as the "Widal reaction," is the most useful (see p. 49). It does not curdle milk, and may therefore be readily spread by means of it. Other important facts in relation to its epidemiology, e.g. the carrier question, have already been mentioned in a previous chapter (p.55). 
Typhoid fever, which is commonest in early autumn, is specially a disease of man, and not, under natural conditions, of the lower animals. The disease is really a general infection of the body. The organism is present in the circulating blood early in the disease, and it tends specially to settle down and damage the lymphoid tissues of the body, e.g. especially that in the small intestine, the mesenteric glands, and spleen; but it is by no means confined to these, and may be found in practically any tissue or organ of the body. In carrier-cases it often persists for long periods in the gall-bladder, and it may be excreted not only in the faeces but also in the urine. Ulceration of the small intestine is one of the most serious results of its action ; and if one of these ulcers perforates through the wall of the bowel, a fatal peritonitis may be set up. Haemorrhage from the ulcerated bowel is another very serious complication, and in some cases lung trouble, abscesses, etc., may occur.

Preventive, and also therapeutic vaccine-treatment is now extensively used, and very favourable results have been reported in our own and in foreign armies.

B. dysenteriae, of which there are numerous closely-allied varieties, is the cause of one form of Dysentery-usually spoken of as Bacillary, as contrasted with Amoebic, Dysentery (see p. 84).

Numerous saprophytic and putrefactive organisms may microscopically resemble members of the Coli-Typhoid group. Most of these, however, e.g., the Proteus group, which are common in the intestine, liquefy gelatin, and show other differences on culture. B. pyocyaneus is a member of a colour-producing group of organisms, and forms a greenish or bluish-green pigment (p. 38), which gives a characteristic coloration to its cultures, and sometimes also to the pus which it may produce in suppurative infections. B. proteus, $B$. pyocyaneus, and similar organisms, though commoner as saprophytes, are frequently found in chronic ear disease, and sometimes in urinary and other infections.

Anaerobic Group of Pathogenic Bacilli.-The pathogenic anaerobes have the common characteristic that they will grow only in the more or less complete absence of oxygen. Some of them are closely allied in other ways : whilst others, for example certain influenza-like organisms, and the $B$. fusiformis (the latter possibly not really a bacillus at all), otherwise differ radically from the group as represented, say, by $B$. tetani or $B$. oedematis, which are its most characteristic members.

Bacillus tetani, the organism which causes Tetanus or Lockjaw, a disease which attacks the horse as well as man, and is 
inoculable into laboratory animals, is very commonly present as a saprophyte in earth, especially in cultivated soil which has been manured with horse- or cow-dung. In the faeces of the former animal it is said to be practically normally present, and therefore not only garden and farm soil but also street- and road-dust usually contain tetanus bacilli; and the diseasecan easily be experimentally produced by inoculating mice or rabbits with a little material obtained from such sources. The organism is an actively motile, slender rod, varying much in length, and most easily recognised when spore-bearing, the spore being terminal and more or less spherical, giving the typical "drumstick" appearance illustrated in Fig. 10, b. In its active vegetative form, it possesses numerous flagella, stains readily, and is Gram-positive.

From its habitat, it is usually mixed with numerous other organisms, often anaerobic like itself ; and with these it may be introduced into a wound and give rise to the disease. Foreign substances such as splinters of wood, grit, and dirt, by the irritation which they produce, may assist its action. As mentioned in a previous chapter, wounds with garden or farm-implements, especially if penetrating deeply-even though comparatively small - or with much contusion or laceration of the tissues, are most liable to be followed by tetanus. In addition to the more usual methods by which the disease is contracted, cases of tetanus may follow the bite of an insect, bullet-wounds, burns, dental operations, infection of the umbilical cord in newly-born children, and even from the therapeutic injection of commercial gelatin if not previously thoroughly sterilised.

Although growing well under anaerobic conditions, the organism is a difficult one to separate in pure culture from the other anaerobes along with which it is usually found. Anaerobic plate cultures may be made; or the mixed culture may be heated, say at $80^{\circ} \mathrm{C}$. for an hour, or at $100^{\circ} \mathrm{C}$. for from a half to ten minutes or more, in the hope of killing off the lessresistant non-sporing organisms. It grows best at body temperature, but it also grows at ordinary room temperature. In stab-cultures in glucose gelatin, or agar it grows best at the deepest part of the thrust, i.e. farthest away from the air, sometimes sending off delicate lateral offshoots, diminishing towards the upper part of the growth, and producing the socalled "bottle-brush" appearance. It causes slow liquefaction of gelatin.

Both in culture and in the living body it produces very active toxins, of which there may be present in a single cubic centimetre of an actively virulent broth-culture, enough to 
kill off perhaps a million mice, if the poison in that amount of filtered broth-culture were diluted and inoculated into them in equal amounts! Much important experimental work has been performed with these toxins, at least two varieties, tetanospasmin and tetanolysin, being present in the toxic broth-culture. The tetanic spasms which are one of the terrible accompaniments of this disease are due to the former of theso toxins, which is absorbed from the area of the wound, more especially along the lymphatic channels of the motor nervesheaths-passing up and attacking the motor nerve-cells of the spinal cord and other parts of the central nervous system, for which it has a strong chemical affinity, and so producing the spasms of the corresponding muscles.

Anti-tetanic serum, if used early, before the nervous system is irreparably damaged, and in large amounts, may save the patient, and should be used even as a prophylactic precaution in cases of wounds the nature of which may render the patient likely to develop the disease.

B. oedematis, the bacillus of Malignant Oedema, is found commonly in garden-earth and manure, often along with the tetanus bacillus, the effects of both being occasionally combined in the same case. It produces an intense, spreading, gangrenous cellulitis, with swelling, oedema, and gas-production, i.e. a combination of necrosis and putrefaction of the tissues. It may extend quickly and produce rapid death.

The bacillus is Gram-negative, motile, and varies much in length, filamentous forms being common. Large oval, more or less central spores are formed. It produces gas in culture, the odour being very offensive, and it liquefies gelatin.

B. chauvaei, the cause of Quarter Evil or Blackleg in cattle ; and B. welchii or B. aerogenes capsulatus, a common saprophytic gas-producing organism which occasionally becomes pathogenic, but is more usually a cause of putrefaction, are other members of the anaerobic group, as is also B. botulinus, the cause of one form of Meat-Poisoning (see p. 41).

\section{The Acid-Proof Group of Bacteria and the Pathogenic Trichomycetes}

The "Acid-Proof" Group of Bacteria.-Certain bacilli in virtue of a fatty or wax-like substance in their protoplasm or cell-body, are somewhat difficult to stain, but, when they are stained by certain special methods (for example, by what is known as the Ziehl-Neelsen Method, where a strong dye, fuchsin, 
is forced into the bacilli by heat and the use of a powerful mordant - in this case carbolic acid) they retain the colour when exposed to the action of a strong mineral acid, such as sulphuric or nitric, even when applied in a concentration of 20 per cent. or more. They are therefore called "acidproof" or sometimes, though rather inaccurately, "acid-fast." Some of the members of this group, when so stained, resist also the decolorising action of alcohol, whilst others do not. The extremely important causal organisms of Tuberculosis and of Leprosy are found in this group, whilst there are in it also numerous other bacilli, either only feebly pathogenic or not cansing disease. These latter are widely diffused in nature, and are found in milk, butter, cheese, ham, water, manure, and on plants and vegetables, as for example in the case of the Timothy grass bacillus. One of them, the Smegma bacillus, is often found upon the surface of the body, especially about the genital region. It is, therefore, highly important to be able to distinguish these more or less harmless saprophytic organisms from the Tubercle bacillus. They usually grow much more rapidly and easily upon culture-media, but the most certain differential test is the inoculation of the guineapig, which is extremely susceptible to tuberculosis, but is unaffected or not affected in the same way by the others.

One point of extreme importance in connection with acidproof bacilli is the possibility that they are merely one stage in the life-history of organisms belonging to a higher bacterial group, the Streptothriceae, and that other phases of their growth and development during which they are not acid-proof may exist. This has been definitely proved in the case of the Leprosy bacillus (see p. 82), and is suspected to occur in that of the Tubercle bacillus itself.

Bacillus tuberculosis. - Little need be said here to emphasize the widespread havoc and destruction wrought by the Tubercle bacillus in man and animals throughout the world. Tuberculosis is the commonest and most important of all bacterial diseases. It can occur at any age; it may affect any organ or tissue of the body, and in many different ways. One in every ten deaths occurring in this country from all causes, is due directly to tuberculosis, and this does not include cases where the disease may be present undiagnosed in persons who die from other diseases-a not uncommon phenomenon. In the decade between 1891 and 1900, the mean population of England and Wales was slightly over thirty millions, and in that period 616,006 persons died of tuberculosis. In the United States in the year 1900 alone, 111,059 tuberculous deaths were reported, and it is estimated that 


\section{ORGANISMS WHICH PRODUCE DISEASE $7 \tau$}

tuberculosis costs the latter country between $\$ 150,000,000$ and $\$ 200,000,000$ yearly !

It is not merely by the death-rate that the damage to the community can be estimated. Thousands are annually weakened and maimed by the disease, and incapacitated for work. Pulmonary forms of the disease attack especially those at the wage-earning period of life, whilst surgical forms in bones and joints permanently cripple and disfigure multitudes of children for the rest of their lives, which are often cut short at an early period.

It is only within the last few years that the public has begun to realise the awful danger to which it is exposed by the prevalence of a disease which can be to a large extent prevented by the proper education of the people in such matters, and by efficient legislation. Such legislation is urgently required, especially in connection with the milk- and meat-supply, proper housing and sanitation, the improvement of workshops, etc. (especially where dust is liable to be inhaled by workmen such as grinders, stone-cutters, quarrymen, and miners - to name only a few), and the prevention of the spread of the disease from man to man, e.g. by spitting in the streets and elsewhere, and in many other ways. Tubercle bacilli may retain their power of producing disease for many months in dried sputum. Heating at $100^{\circ} \mathrm{C}$. for an hour may not kill the organisms if dry. In a fluid such as milk, it takes some fifteen to twenty minutes to kill them at a temperature of $60^{\circ}$, and, unless the heating is performed in a closed vessel, many may escape in the cooler pellicle on the surface of the fluid next the air. Actual boiling at $100^{\circ} \mathrm{C}$. usually kills them in five minutes. Five per cent. carbolic added to sputum may take as long as twenty-four hours to penetrate and kill the bacilli. Corrosive sublimate, from its property of coagulating the surface of such material, is not a suitable disinfectant; lysol being a much more efficient agent, as it acts upon and dissolves the sputum, and so reaches and destroys the bacteria.

Infection is carried by the cough of the consumptive, as well as by contaminated dishes and the like. The chief methods of spread have already been discussed at some length in Chapter VI.

The Tubercle bacillus, which was discovered by Koch in 1882, is a minute rod-shaped organism (see Frontispiece, fig. 12). It often shows a slight curve, and this appearance may be accentuated by the fact that the bacilli may remain united end to end, at a slight angle to one another. They are also often found in little sheaf-like groups or masses, and the individual bacilli frequently show numerous little granules along 
their course, sometimes appearing as a row of dots. When stained by the Ziehl-Neelsen carbol-fuchsin method, the tubercle bacillus will withstand the action of 20 or 25 per cent. sulphuric acid and of alcohol for many hours, and is the most resistant member of the acid-proof group in this respect. In certain tuberculous material such as old caseous glands it is often difficult or impossible to demonstrate any acidproof bacilli by this method, yet such tissues, if inoculated into the guinea-pig, reproduce the disease. By recent staining methods such as those introduced by Professor Much (the GramMuch Method), certain more or less irregular granules may bo found, and these are believed now to be a non-acid-proof and still infective phase of the life-history of the organism.

- The bacillus was first cultivated artificially by Koch upon sterilised and inspissated ox-serum. Blood-serum and various egg-media, especially if smeared with a little sterilelhuman blood, are used for obtaining primary or original cultures. The suspected tuberculous material is first inoculated into a guinea-pig or rabbit, or it may be treated with a powerful solvent such as "antiformin," which rapidly dissolves up and destroys other non-acid-proof bacteria and tissue elements, but, if not too long applied, leaves the Tubercle bacillus unharmed. Primary cultures are then made upon the media mentioned, from the lesions resulting in the animal, or from the washed and centrifugalised deposit from the antiformin-treated material. The organism grows very slowly, becoming apparent usually in about ten days or more, and gradually increasing for weeks or months. Secondary cultures of some strains of the bacillus grow well on agar and potato, and in broth, if glycerin is added to them. Sterile animal tissues may also be used as a culturemedium. The growth may be dry and wrinkled, or it may be scaly, wax-like, or crumb-like. In such cultures, involution and thread-like forms are common, and often show a marked granular appearance on staining. Branching forms, suggesting the possible streptothricial nature of the organism, are sometimes found.

The effects of its action upon the tissues of the body are so protean and complex, that special works on pathology must be consulted by those who wish to understand them. It is sufficient here to explain that the toxins of the bacillus possess the power of causing the gradual or sometimes rapid death of the tissues locally by a necrotic process known as caseation. The tissues around the bacillus, if not too seriously damaged, are stimulated to proliferate in a peculiar manner, and attempt to surround and shut in the organism by a slow fibrous tissueformation around it. By a combination of these two processes 
of destruction and proliferation are produced the nodules or tubercles from which the disease has received its name. These tubercles vary from minute microscopic nodules to large potato-like masses, the latter variety tending to be especially found in cattle. Extensive softening of tuberculous areas may occur, giving rise to tuberculous or "cold" abscesses ; or, as in the case of the lungs, where the contents can be evacuated through the bronchial tubes, producing phthisical cavities. Within the body, unless the disease is arrested, it tends to spread progressively, both locally and to distant parts along the lymphatics and blood-vessels. Iymphatic glands, serous cavities, as well as the lungs and other tissues, are specially liable to invasion, and in the young subject the bones and joints, as well as the glands, etc., are very commonly attacked.

In any given case, the two antagonistic processes of toxic destruction and tissue proliferation may occur each in varying degree, according as the bacilli or the tissues gain the upper hand. General toxic effects such as emaciation and sweating, etc., and symptoms depending on the site of the lesion, such as cough and spit, haemorrhage, and the like, are in some cases familiar evidences of the disease.

Different Strains or Types of the Tubercle Bacillus.Almost all animals are, or may be rendered, susceptible to tuberculosis in varying degree. Man and cattle are extremely liable to the disease, as are also various domesticated and $\operatorname{tam} \theta$ animals. From 15 to 20 per cent. of cattle killed in slaughterhouses in this country are reported to be tuberculous, and of pigs from 2 to 3 per cent. With more thorough inspection it is probable that these figures would be found to be considerably under the mark. Many animals which do not in natural surroundings take the disease often die of it under artificial conditions, e.g. in menageries and zoological gardens, or when kept as domestic pets. The disease is less common among horses and sheep. Laboratory animals such as guinea-pigs and rabbits, though not naturally subject to the disease, are extremely suscepiible to artificial inoculation. The disease is also found in birds, especially in poultry - fowls, turkeys, pigeons, and hand-reared game-birds such as pheasants-and is then known as Avian tuberculosis. It-or at all events a closelyallied disease-may even be found in reptiles, amphibians, and fishes, and a similar disease has been found in certain invertebrates. It is therefore a question of vital importance to determine whether the bacilli producing tuberculous diseases in animals are or are not identical with one another, and are capable of infecting man. An enormous amount of work has 
been carried out upon this subject, and it has been found that there are certain slight differences, e.g. between what may be called the Human, the Bovine, the Avian, and the ColdBlooded and other Types of the Bacillus; but the point of greatest importance is that the Bovine, as well as the Human, Type, can and does produce the disease in man. For the methods of differentiation of the bacilli, various cultural, and more especially inoculation, tests are used; and there are also certain very slight morphological differences. If the bovine bacillus is inoculated into a rabbit's knee-joint, an acute generalised and rapidly fatal tuberculosis occurs. If the human type is similarly injected, the resulting lesions are much less acute, and remain small and few in number and may not kill the animal. In a very valuable series of such experiments by Fraser, ${ }^{1}$ in seventy cases of surgical tuberculosis in children, forty-one showed the bovine bacillus, twenty-six showed the human type, and in three cases both types were present. In Edinburgh, abdominal tuberculosis accounts for between three and four per cent. of all the medical cases admitted into the Children's Hospital ; in Glasgow between four and five per cent. The great majority of these abdominal cases are due to the bovine bacillus, and the infection is caused by tuberculous milk. In older persons, especially where the disease affects the lungs, the human bacillus is more usually found, but in adults too, the bovine bacillus also plays an important part. ${ }^{2}$ Milk for the feeding of children should therefore, in spite of the foolish prejudice against this procedure in some quarters, be carefully sterilised, though in the future it is to be hoped that a pure milk-supply will be available-a condition which is very far from being fulfilled at the present time.

Amongst cattle, the disease-the incidence of which steadily increases with the age of the animal-may be communicated directly or indirectly by the discharges from the lesions, whether respiratory, alimentary, or genito-urinary, by the milk, especially in mastitis or udder-disease, and by the excreta contaminating pastures, foeding-troughs, fodder, or milk.

A vast amount of work has been done in the attempt to produce immunity against the disease. Great numbers of

1 "The Relative Prevalence of Human and Bovine Types of Tubercle Bacilli in Bone and Joint Tuberculosis occurring in Children." John Fraser, M.D., Assistant Surgeon to the Sick Children's Hospital, Edinburgh. Journal of Experimental Medicine, 1912, vol. xvi. p. 432.

2 Since the above was written, an important paper by Dr. A. Philp Mitchell, entitled "The Infection of Children with the Bovine Tubercle Bacillus," has appeared in the British Medical Journal for Jan. 17, 1914, p. 125, fully emphasizing the truth of this statement. 
differently prepared vaccines, usually spoken of as tuberculins, have been and are being extensively used both for diagnosis and treatment. What is known as Koch's Old Tuberculin is prepared either from the human or the bovine bacillus by sterilising, concentrating, and filtering a glycerin-broth culture of the bacillus ; and is used extensively for the diagnostic Tuberculin Test in both man and animals. Scarification, inunction as an ointment, and subcutaneous injection methods each have their advocates. The last-named method is that used in the testing of cattle, Perlsucht Tuberculin (i.e. that prepared from the bovine bacillus) being used. In some advanced cases of the disease, both in man and in animals, the test may give a negative result, and another possible source of fallacy-unfortunately sometimes made use of by unscrupulous dealers-arises from the fact that, even in a diseased animal, a previous inoculation with tuberculin may prevent the appearance of a positive reaction.

With regard to the therapeutic use of the tuberculins, it can only be said that in suitable, and especially in early, comparatively non-progressive localised cases of the disease where there is no fever, and when given with scrupulous care as regards the graduation of its dosage, it may be regarded as an adjuvant to other treatment. In progressive and especially in advanced cases, and if too large doses are used, it may do infinite harm, producing increased activity, even in old and partially healed lesions, and lighting up, it may be, a generalised and rapidly fatal tuberculosis.

Treatment with antituberculous sera has also been used, but is still more or less unsatisfactory and in its experimental stage.

Bacillus leprae is the cause of Leprosy, an infective and contagious disease characterised by its slow onset and chronic course, and the terrible disfigurements and mutilations which it produces in its victims. The disease, which has been known from the most ancient times, was once widely spread over the globe, but is now rather tropical and sub-tropical in its distribution, though still also found in Norway, Russia, Newfoundland, and elsewhere. It used formerly to be endemic in this country, but has now been stamped out, though one or two cases in persons who have never been out of the country have been reported. The lesions are characterised by destruction and absorption of the tissues, with a certain amount of fibrous formation. The disease may attack any organ or tissue, but is specially found in the skin and subcutaneous tissues, mucous membranes (e.g. of the eye, nose, etc.), the various glands of the body, and the trunks of nerves, especi- 
ally of the skin. When the nerves are invaded, patches of anaesthesia and loss of the normal pigment of the skin occur, the latter phenomenon giving rise to the description, "a leper white as snow." The method of infection, which is not yet fully understood, may be perhaps direct from individual to individual, or it may be transmitted by parasites such as the louse.

The bacillus in its acid-proof stage is very like the tubercle bacillus, though usually a little thicker. It has only recently been successfully cultivated, and has been found to be pleomorphic, i.e. found in different forms, four such forms being now described, viz. (1) acid-proof bacillus, (2) non-acid-proof bacillus resembling a "diphtheroid" organism (see p. 67), (3) an acid-proof and (4) a non-acid-proof Streptothrix (seo p. 15). Treatment with vaccines has met with some success, the reactions obtained proving the specific nature' of the organisms cultivated.

\section{The Pathogenic Trichomycetes}

The Trichomycetes or Filamentous Higher Bacteria are more or less intermediate in position between the Lower Bacteria and the Higher or True Fungi such as the Moulds and Mildews. The most important disease-producing members of this group are branching organisms which for convenience, though perhaps not with scientific accuracy, may be classed together as the Streptothriceae.

Streptothrix actinomyces, the cause of Actinomycosis, may be taken as the most important member of this group, though disease in man may also be produced by certain other closelyallied organisms, e.g. one form of Madura foot or Mycetoma by Streptothrix madurae, and a variety of Pyaemia by Streptothrix (or Cladothrix) asteroides. Actinomycosis is especially a disease of cattle in which it causes the characteristic conditions known as "Woody Tongue," "Lumpy Jaw," etc.: and when communicated to man there is a tendency to the breaking down of the lesions, with chronic abscessformation or ulceration, and the discharge of pus containing yellowish or greenish granules which contain, and are largely composed of, the organism. Infection usually occurs through the mucous membrane of the mouth, pharynx, oesophagus or intestine, the neighbouring tissues becoming invaded, usually with abscess-formation. In some cases the air-passages and lungs are the site of infection. Generalised infection may occur by the blood-vessels, with widespread secondary lesions in the liver, lungs, brain, or bones. 
Both in the tissues and on culture, the organism, as its name Actinomyces or Ray-Fungus implies, tends to grow in a radiate branching fashion. The filaments (see Frontispiece, figs. 16 and 17), which are Gram-positive, often show a dotted or granular appearance enclosed in a delicate sheath, which may, especially in the lesions in cattle, undergo a peculiar degenerative swelling known as "clubbing," this change being especially found at the periphery of the colonies. Calcification may ensue, with disappearance of the filaments. Rounded or coccus-like bodies are also described as occurring in the lesions. The filaments, especially in culture, often show a tendency to break up into bacillus-like elements, a point of interest in relation to certain phenomena already described in connection with the acid-proof group of bacteria (p. 76 et seq.).

On culture, the streptothrix grows readily on potato and on wheat-paste, the organism being in nature a parasite-a form of "smut" - of cereals (wheat, barley, etc.), from which the infection in cattle, and not infrequently in man also, is derived. It also grows on agar and in gelatin and broth, especially if glycerine be added. On a surface, the growth is raised dry, tough, and brittle, and may resemble beeswax, or may be scablike. In gelatin, which is slowly liquefied, and in broth, there is a tendency to grow in little fluffy balls, somewhat resembling the granules found in the pus.

\section{Pathogenic Yeasts and Moulds}

The Blastomycetes or Yeasts (see Frontispiece, fig. 18) differ from the Bacteria in their mode of reproduction, which in the former is by gemmation or budding (instead of, as in the latter by fission). In some of them, the Saccharomycetes, endospore (ascospore) formation also occurs ; whilst in the Torulae, budding alone is seen. In man, the yeasts may produce certain rare forms of ulcerative skin disease (Blastomycotic Dermatitis), and even occasionally a generalised infection with the production of tumour-like masses in the bones and organs.

The Hyphomycetes or Moulds are characterised by the formation of a felted network of threads - the mycelium-and by the production of fruit-bearing hyphae which are familiar to everyone as the velvety or cotton-wool-like appearance of a mouldy surface, green or white or black as the case may be. These aerial hyphae carry the sporangia in which the oval spores are developed, sometimes preceded by a form of sexual reproduction. The common white mould (Mucor mucedo), green 
mould (Penicillium glaucum), and black mould (Aspergillus niger) are familiar examples. They may occasionally be associated with disease, but the most important pathogenic moulds are the group which cause Ringworm in man and animals, Favus (Achorion schoenleini), Pityriasis Versicolor (Microsporon furfur), and certain rarer diseases of the skin and hair.

Of diseases caused by the Ringworm group, some 80 or 90 per cent. of the cases in children are due to the Microsporon audouini, or small-spored variety, which invades the hairs and causes them to break off short. The large-spored fungus contains two groups, one variety of which especially attacks the interior of the hairs and is therefore called Trichophyton megalosporon endothrix: and another, found especially in animals and communicated from them to man, grows chiefly on the outside of the hairs, and is therefore known as Trichophyton megalosporon ectothrix. The former attacks the hair in older children, and the latter usually attacks the face, nails, or body, and may be found in adults. These fungi give characteristic heaped-up, mould-like growths on culture, and grow best on agar or gelatin to which beer-wort has been added, or upon maltose-agar.

The Thrush Fungus, Oidium albicans, which is often found in the mouths of weakly children and produces white patches on the tongue, gums, or cheeks, shows a mixture of a threadlike mycelium and yeast-like bodies.

Sporotrichosis is a rare condition found in the skin and subcutaneoustissues, in which situations nodules form, break down, and ulcerate. It is due to the Sporotrichon beurmanni, the exact classification of which is still somewhat doubtful.

\section{The Pathogenic Protozoa}

The classification of these has been given upon p. 13, and of late years an enormous amount of work has been done in connection with organisms of this nature producing disease in man and animals. The literature is very extensive, and we shall content ourselves with the description of the parasites which cause Amoebic Dysentery, Sleeping Sickness, Spirochaetosis, and Malaria.

The Protozoa usually have a very complicated life-history, and as a rule require more than one species of animal host in which to carry out their complete developmental cycle.

Entamoeba histolytica.-This organism is the cause of true Tropical Dysentery, as opposed to the bacillary form described on p. 73. It belongs to the Class Sarcodina or Rhizopods, 
and is found in the stools and in the walls of the intestine and also in the liver-abscesses so often present in cases of tropical dysentery (see Frontispiece, fig. 21). The parasite may also find its way into blood-vessels. It measures 25 to $30 \mu$ in diameter, and in one stage is actively amoeboid, i.e. moves and captures its food by the projection of pseudopodia or projections of its protoplasm, especially of an outer clear layer known as the ectoplasm. Within this is the endoplasm, which usually has a peculiar "vacuolated" appearance, and in which is situated a rounded nucleus which is poor in chromatin or colouring matter and therefore difficult to stain. The parasite feeds upon leucocytes, red blood-corpuscles, and other cells of its host, and upon starch-granules, food-debris, and bacteria in the intestine. It multiplies by fission, and by simple and multiple budding. When in unfavourable surroundings, it becomes rounded and enclosed in a thick wall or capsule, within which spores are formed. These pass out with the faeces and carry the infection, as has been proved by experiments on the cat. It has also been successfully cultivated artificially in association with intestinal bacteria upon which it feeds.

Trypanosomes belong to the class Mastigophora or Flagellates (see p. 14), and are parasitic in the blood of many animals such as mammals, birds, amphibians, and fishes. Trypanosoma lewisi is very common in the rat, and $T$. brucei is the cause of Nagana or Tse-tse Fly Disease, a terrible scourge of cattle and horses in certain parts of Africa. Numerous other forms cause various diseases in horses and cattle and other animals in many countries of the world, but in man the most serious form of disease so produced is Sleeping Sickness caused by Trypanosoma gambiense. ${ }^{1}$ This is a small eel- or fishlike, actively motile parasite (see Frontispiece, fig. 22) which, under the microscope, can be seen swimming with a wriggling movement and also propelled by means of a fin-like undulating membrane along one side of its body. This membrane is prolonged at the anterior end into a whip-like flagellum. The organism is about $20 \mu$ or more in length, and it multiplies either by direct fission or by a complicated form of sexual reproduction, for the completion of which a biting fly, Glossina palpalis or some of its relatives, is required, these flies constituting the carriers of the infection among man and animals. In Uganda about a quarter of a million natives-more than two-thirds of the entire population-have perished of this

1 Trypanosoma rhodesiense is another closely allied organism which produces practically identical results. 
disease in the last six or seven years ; and other parts of Central Africa have been entirely depopulated. In the earlier stages of the infection, the patients do not show much more than perhaps some enlarged glands in their necks, but later, when the parasite enters the cerebro-spinal fluid, they become emaciated to mere skeletons and suffer excruciating agonies, often going mad before the inevitable fatal termination of their illness. It is hoped that by the isolation of cases, and iby the clearing out of the fly-infested belts of reeds and brushwood around the towns and villages, much may be done to limit the ravages of this disease ; but it is suspected that the wild gameanimals, hitherto carefully preserved, may act as reservoirs of the disease, and these may in the interests of man require to be exterminated before the disease can be finally overcome, if further investigation is found to confirm this suspicion.

Spirochaetes. - There is considerable difficulty and confusion in the classification of organisms of this group and those which morphologically resemble them; and the proper place and name of many such organisms has not yet been decided.

Spirochaetes are probably Flagellate Protozoa, though some believe them to be bacteria belonging to the Genus Spirillum. They are long, thin, wavy or spiral, thread-like organisms, usually with pointed ends (see Frontispiece, figs. 19 and 20).

Spirochaeta pallida (or Treponema or Spironema pallidum) is the cause of Syphilis-whether Congenital or Acquiredin all its protean forms. The disease is communicated usually, though not exclusively, by direct contagion, and especially by sexual intercourse (see p. 55). The primary lesion, produced by local inoculation, usually shows as an indurated or hard. chancre, though this is occasionally not found. From the original sore the disease spreads by lymphatics and later by the blood, with enlargement of lymphatic glands, sore throat, headache, skin-rashes, and invasion of any or all the organs and tissues of the body, the blood-vessels, liver, kidneys, spleen, nervous system, and bones and joints often specially suffering. There is no pathological distinction between the so-called primary, secondary, and tertiary stages of the disease, which are purely artificial and retained for clinical convenionce. The changes once started, unless promptly treated thoroughly and efficiently by medical means, are progressive and go on indefinitely after infection, often for the remainder of the patient's life, and may kill him in a hundred different ways, by attacking and destroying some vital organ or by causing progressive disease of the blood-vessels and nervous system. They are sometimes rapid, but often extremely chronic, in their 
course. Aneurism, kidney-disease, cerebral haemorrhage, and general paralysis of the insane are only a few of the possible conditions produced by this widespread and insidious disease, and our asylums are full of cases of lunacy brought on by it.

It may be communicated by the mother to her child whilst still in the womb, or at birth, a tragedy seen with appalling frequency, and leading either to early death, or to disease and deformity, impairment of growth and intellect, as the lesions tend to be very widespread and attack the organs and tissues during their active period of development and growth.

Accidental inoculation of the innocent is all too common, and the surgeon and the obstetrician, the midwife and the nurse, the innocent wife and even children, are all too often victims to this fell disease through no fault of their own. Of a truth the public requires to know what a scourge is in its midst, and education of all to its dangers is urgently required. Both sexes alike should know of these matters at an age before the danger is likely to be encountered.

The "Spirochaete" is a minute, corkscrew-like, actively motile organism, and may be present in enormous numbers in the lesions. It long eluded discovery owing to the fact that it is very difficult to stain, but numerous special methods are now used for its detection, such as staining with silversalts, silhouetting with Indian ink or with finely divided metallic silver, or examination whilst still living by the darkground illumination method. Various serological tests, of which the best and most widely known is the Wassermann reaction, are also used for the diagnosis of the disease, and are applied to the blood-serum or cerebro-spinal fluid of the patient.

The discovery by Ehrlich, and his pupil Hatta, of Salvarsan or " 606 " for the treatment of syphilis is a triumph of patience and experimental skill, and is now so well known that we need only mention it here. Its use along with the older mercury and other treatment has put in the hands of the medical profession a powerful weapon against the ravages of the disease.

A very similar parasite, the Spirochaeta pertenuis (or Treponema pertenue), is the cause of Yaws, a disease found in many parts of the tropics, especially the West Indies, West Africa, Ceylon, Assam, Burma, and the Pacific. Both Syphilis and Yaws have been inoculated into monkeys.

Blood-Spirochaetes of various kinds produce infection of fowls, geese, and other birds; Relapsing Fever (S. obermeieri or recurrentis), probably carried to man by the common bed-bug ; Tick Fever (S. duttoni), carried by a tick, tho Ornithodorus moubata, and many others. A form of 
membranous ulceration of the mouth and throat, not at all uncommon in this country, especially among children, known as Vincent's Angina, is characterised by the presence of a Spirochaete in association with a peculiar spindle-shaped organism, B. fusiformis (see Frontispiece, fig. 20). The exact position of these organisms in the scale of classification is still more or less undetermined.

Some spirochaetes, including the organism of syphilis, have been recently successfully cultivated, and it is possible that a diagnostic test-the luetin reaction-analogous to the tuberculin and mallein tests, will now be available in the case of syphilis.

Malaria Parasites.-The organisms which cause Malaria in the human subject belong to a group of the Class Sporozoa known as the Haemosporidia, all of which are blood-parasites which usually possess two specific hosts-the one usually a vertebrate such as man, in whose body an asexual cycle of development by fission or schizogony occurs, corresponding in its periodicity with the attacks of the fever; and another invertebrate host, usually a biting fly of the mosquito tribe; in which a sexual cycle or sporogony is completed. These two life-cycles are very complex, and were first worked out with much patient labour by Ronald Ross in a form of bird malaria. There is still a good deal of variation of opinion as to the exact nomenclature and classification of the malarial parasites of man. At least three types of malaria are recognised, and their parasites, which possess many synonyms, are:

Plasmodium vivax, the cause of Benign Tertian Malaria, with a life-cycle in man of about forty-eight hours, the attacks occurring every second day.

Plasmodium malariae, the parasite of Quartan Fever, in which the attacks come on every third day.

Plasmodium immaculatum (or Laverania malariae), the cause of Tropical, Pernicious, or Aestivo-Autumnal, or Malignant Tertian Malaria.

These three parasites are distinguished by their morphology and by their pathogenic effects upon their host. Each has a somewhat similar developmental cycle. In man, a young parasite, which is amoeboid, fastens upon and enters a red blood-corpuscle in which it grows and upon the substance of which it feeds. It then goes on to form (1) a rosette-like body which proceeds to divide into small spherical bodies, the red corpuscle is destroyed, and these small parasites are freed into the blood (this phase corresponding to the acute attack or paroxysm of the fever), and invade fresh blood-corpuscles; 
or (2) sexual cells, male and female, which in the benign tertian and quartan parasites are rounded, and in the pernicious or malignant tropical form are crescentic in shape. For the conjugation and further development of these sexual cells, or rather of their products, the blood containing them must be sucked into the "stomach" or mid-gut of a female mosquito of the Genus Anopheles. The cell formed by their union elongates and burrows its way through the insect's gut-wall, on the outer side of which it becomes encysted. After a series of complicated changes, during which the cyst enlarges, great numbers-as many as 10,000 - of minute, elongated, threadlike bodies with pointed ends develop in its interior. These are then liberated into the body-cavity of the mosquito and actively migrate to the salivary glands at the root of its proboscis, ready to be inoculated by the insect into the blood of the next human victim and attack his red blood-corpuscles, and so complete the cycle of development of the parasite.

As the Anopheles mosquito is thus necessary for the spread of the infection, much good work has been done towards the prevention of the disease by attempting to exterminate this insect-carrier-by draining pools and marshes or by pouring paraftin oil into them. The young of the mosquito hatch and develop in such stagnant pools - and even in rainwater accumulating in old tin cans, water-barrels, or basins. They require to come to the surface at short intervals to breathe, and the thin scum of oil, spread over the surface of the water, prevents them reaching the air and they are thus asphyxiated. Another well-known precaution is the use of mosquito-nets or curtains to prevent the female insects from biting their human victims during the night, which is the period of their activity. The therapeutic action of quinine for the destruction of the parasites in the human body is, of course, also common knowledge.

\section{CHAPTER VIII}

BACTERIA AND PLANTS-BACTERIA IN THE ARTS AND INDUSTRIES-COMMERCIAL BACTERIOLOGY

\section{Bacteria and the Nitrogen Cycle-Bacterial Diseases of Plants}

Nitrification of the Soil.-One of the important chemical elements necessary for plant-life and nutrition is Nitrogen, a large proportion of which has to be provided in an assimilable 
form by the action of saprogenic organisms of the soil. These attack the organic animal and vegetable matter such as manure, decaying leaves, etc., and break up their protein constituents with the formation of, amongst other substances, Ammonia, which combines with potassium and sodium and other inorganic elements in the soil to form Ammonium Salts of these substances. Certain bacteria then have the power of causing the oxidation of these ammonium salts to nitrites. Another set of bacteria effects the oxidation of the nitrites into nitrates, the latter of which can now be absorbed and utilised by the plants growing in the soil. It is interesting and important to note here that certain other bacteria have the power of de-oxidising or reducing these nitrates, and, if these are present in a soil in great numbers, their action is very harmful, as they de-nitrify it, and thus undo the beneficent action of the nitrifying group described above.

Nitrogen-fixation by Soil-Bacteria and by Root-Nodule Bacteria.-Another important means by which nitrogen is supplied to plants is by the instrumentality of another group of bacteria which can seize upon the Free Nitrogen of the Air and by various chemical processes transmit it to plants. Some of these bacteria are free in the soil, but another very interesting group has the peculiar property of entering the roots of leguminous plants such as clover, beans, peas, lucerne, vetches and the like, giving rise to tumour-like swellings known as Root-Nodules - a sort of symbiosis, or "living together" in a partnership beneficial to both plant and bacterium. Interesting experiments have been carried out by growing such leguminous plants in soils respectively rich and poor in these bacteria or completely sterilised by heat and so bacteria-free. The plants grown in the former flourish and outgrow those in the latter, which often remain stunted and poorly developed. Much was at first hoped for by the artificial use of these bacteria as soil-fertilisers, but the actual results so attained in practice have as yet been somewhat disappointing. The rotation of crops, with the periodic sowing of nodule-bearing leguminous plants, such as clover, or vetches, is the usual method by which such bacteria and their resulting nitrogen are increased in amount in the exhausted soil.

Bacterial Diseases of Plants.-Plants, no less than animals, are subject to various bacterial, protozoal, and other forms of infective disease. Various Blights and Rots, Wilts, LeafSpots, and even Tumour-like Nodules and Excrescences may be caused. Pear-Blight is caused by a motile bacillus, $B$. amylovorus, which is probably carried from infected trees and 
inoculated intu others by bees and other insects. Brown Rot in tomatoes and potatoes is due to $B$. solanacearum, and Cucumber Wilt is produced by B. tracheiphilus carried by insects such as the potato-beetle. Black Rot in cabbages, cauliflowers, and turnips, is due totheir invasion by $B$. campestris, a short motile bacillus which passes into and blocks the vascular channels in the leaf-stalks, stems, and roots, producing a black discoloration with softening or rotting of the tissues.

Many other bacterial diseases of plants are now known, and for a description of these, reference should be made to the important books by Erwin F. Smith, published by the Carnegie Institute of Washington.

\section{Bacteria in the Arts and Industries-Commercial Bacteriology}

As we have seen in our introductory chapter (p. 17), presentday bacteriology practically owes its origin to the work of Pasteur upon Fermentation. We have already touched upon the importance of bacteria in Agriculture, some organisms being useful, others harmful to the growth of plant-life. The scientific farmer must also know something of the many bacterial and other diseases which may attack his stock, and which help or hinder the work in his dairy. We have already touched upon some of these questions incidentally in other connections (the transmission of disease from animals to man, and by milk, etc.), and we may here merely refer to the part otherwise played by Bacteria in the milk-industry.

Milk-Products : Butter-Making.-It has long been known that milk and cream from which the best butter is obtained should be "ripened" for a couple of days before the butter is made. This ripening is effected by the action of suitable bacteria known as "starters." In the old-fashioned roughand-ready methods still mostly in use in this country, these are left chiefly to chance and good luck, the milk and cream being soured either by adding a little of last day's churning or by leaving them to be inoculated with any of the stray organisms with which the dairy teems. In other countries such as America, Denmark, and Germany, where the applications of scientific inquiry are more rapidly assimilated and put to a practical use in the industries, and to a slight extent in this country, such "starters" as are known to produce the best results are now cultivated and added scientifically in order to bring about this ripening, and different flavours can be produced in the resulting butter to suit the taste of the consumer. Most of these starters are members of the Lactic Acid 
Bacillary Group, but other organisms are also used. A suitable temperature, $20^{\circ}$ to $30^{\circ}$ Centigrade, and cleanliness conforming more or less to a bacteriological standard, together with a preliminary pasteurisation before adding the starters, are essential to true scientific butter-making, but as yet even a rudimentary knowledge of these important facts is not within the range of an ordinary dairy-farmer's education! The scientific dairyman should also know of the existence of starters of a hurtful type, which lead to the production of butter having a rancid, bitter, oily, or otherwise objectionable taste. At present he explains to the unsuspecting public that the "turnipy taste" of his butter is inevitable, as the cows are being fed upon turnips, instead of informing them that the taste is really due to organisms, especially of the $B$. coli type, which are inoculated into the milk and cream from cow-dung and other even more objectionable sources.

Cheese-making also owes its success or failure to the presence of suitable organisms - various Bacteria, Moulds and Yeasts. The casein or coagulable protein of milk is usually first precipitated by the action of rennet. The ripening of this casein is then carried out, either by the haphazard, or by the scientific inoculation with the special group of organisms characteristic of the type of cheese to be made. "Diseases" of cheese, like those of butter, are caused by the presence of harmful organisms which may make it bitter or rancid or even absolutely putrid, or it may be broken up or rendered spongy by gas-producing bacteria.

Koumiss, made from mare's milk, Kefir, made from cow's milk, and other forms of Fermented Milk are produced by the action of certain bacteria which by their action render the milk-curd more digestible and therefore sometimes useful as a diet for invalids.

The Retting of Flax and Hemp.-In order to separate and obtain the fibres of flax and hemp, from which linen and ropes, string, etc., are respectively made, the stems of these plants are rotted or retted in water or upon damp ground in order to soften them and allow of the isolation of the fibres. This rotting is really a modified process of putrefaction, and is brought about by the action of certain specific bacteria. Cocoanut fibre is similarly obtained.

Tanning.-The characteristic odour of a tannery is a somewhat unpleasant reminder that bacteria are closely concerned with many of the processes carried on within its precincts. After Drying and Salting, the hides are cleared of hair either 
by a special form of putrefaction or by chemical means. They are then steeped in a fluid which is concocted from the manure of poultry, dogs, and similar peculiar sources, bran, etc., in which they are allowed to ferment, and then transferred to the barkor tan-pit, where a further process of fermentation takes place.

Sewage-Works and Ensilage.-In ordinary sewage there are enormous numbers of bacteria present-from one to ten or twelve million per cubic centimetre, in comparison with which numbers it may be of interest to refer to the table on pp. 53-4, from which it will be seen that milk as purveyed to the public often contains as many organisms as liquid sewage!

In order to get rid of the solid and semi-solid constituents of sewage, it is often allowed to putrefy and become liquefied so as to render its disposal easier. The old-fashioned cesspool and cesspit owed their use to this object. On a larger scale, sewage may be stored in covered tanks or reservoirs and allowed to undergo anaerobic putrefaction for a day or two. The "sludge" so obtained is passed through coarse filters in which further putrefaction and liquefaction in presence of airoccurs, and the effluent is passed into a river or the sea, or utilised as manure on an ensilage farm.

The Curing of Tobacco. - The ripening of the dried leaves of the tobacco-plant, during which process they are fermented in heaps or piles, is probably to some extent brought about by the action of bacteria, the varying characters of which help, along with other factors, to give the various tobaccos their special flavour and aroma.

Fermentations in Baking.-Wheat-flour and water, in the form of dough, forms a very easily fermentable substance, and if this fermentation is allowed to occur all through the mass, innumerable little cavities are formed by the liberation of gas, usually carbon dioxide $\left(\mathrm{CO}_{2}\right)$, which give the characteristic sponginess to the bread or other products of the bakery. This fermentation is usually started by adding some brewer's yeast, or if preferred, pure cultures of yeasts, or by mixing in some leaven or dough already fermented at a previous baking. The mass is allowed to stand for several hours at a suitable temperature, during which time the fermentation andgas-production occurs. The fermented dough is then divided up and baked in the oven, the imprisoned gas expanding and making the bread light and spongy. Changes of a very complicated nature take place, both during the fermentation and the heating, such as the production of a certain proportion of sugar from the starch. 
The sugar is fermented by the yeast with the production of the gas and a small amount of alcohol. The gluten of the wheat is rendered soft and digestible. During the heating, the yeast is killed off, starch granules are ruptured, the albuminoid constituents are coagulated, and some of the starch is converted into dextrin, especially in the outer portion or crust.

Various physical and chemical methods have from time to time been introduced to replace the yeast-fermentation. Aeration by the mechanical forcing of carbonic dioxide gas into the dough, or by the freeing of the gas from various baking powders on heating the bread, are not infrequently used, but in none of them is the resulting bread so well flavoured and digestible as that made by the older methods with yeast or leaven.

Alcoholic Fermentation.-In 1837, three investigators, Kützing, Latour, and Theodor Schwann, independently discovered that alcoholic fermentation was due to a living organism in the "Yeast." Their discovery was met with ridicule at the hands of the great chemists and other scientists of their time; and it was not till Pasteur announced, in 1857, that he was "of opinion that alcoholic fermentation never occurs without simultaneous organisation, development, multiplication of cells, or the continued life of cells already formed," and subsequent research by others confirmed his statement, that its truth was recognised and accepted. The chemistry of the process is one of great complexity. In a recent important monograph on "Alcoholic Fermentation" by Dr. Arthur Harden, it is stated that "the sugar which has diffused into the (yeast) cell unites with the fermenting complex and undergoes the characteristic reaction with phosphate, already present in the cell, yielding carbon dioxide, alcohol, and hexose-phosphate."

Beer, in all its numerous forms-ale, mead, porter, and the like -is the result of two chemical processes: (1) the conversion of the starch in the germinating seeds of various cereals such as barley, maize, oats, wheat, and rice (the first-mentionedbarley-being the most important) into sugar under the action of the ferment diastase. Germinating barley contains the necessary starch and diastase ferment in the fullest amount, and barley-malt, as the resulting product is called, is most used for brewing in this country. The germinating barley is killed by heat, dried, crushed between rollers, and treated with hot water in the mast-tun to form a wort (that is, the clear, sugar-containing liquid which contains the products of the alteration or conversion of the starch), which is then boiled with hops, filtered, cooled, and: (2) fermented by the addition 


\section{BACTERIA IN ARTS AND INDUSTRIES 95}

of the requisite amount of yeast. An ounce of this yeast contains something like 5,000,000,000 cells, the chief organism present being the Saccharomyces cerevisiae. As mentioned on p. 18, "diseases" of beer (such as a disagreeable bitter flavour, persistent turbidity, bad smell, and the like) may be due to the presence of undesirable forms of Saccharomyces.

For further details of this complicated process, special books on brewing should be consulted. It is sufficient for our purpose here to summarise the changes which occur as (1) the production of fermentable sugars from the starch of the grain, and (2) the fermentation by the yeast of the sugars so produced, with the formation of alcohol and other by-products.

Whisky is a grain-spirit prepared from malted barley, the fermented liquid being then distilled.

Wines are alcohol-containing beverages prepared by suitable fermenting the sugar present in the juices of various fruits such as grapes, currants, apples, etc., or from rhubarb, or even in some cases, from flowers such as the elder-flower or cowslip -grape-juice being, of course, the most important source. The fermentation is due to special wine-yeasts, which may either be present on the fruit naturally, or may be added artificially.

Many other industrial processes are, in whole or in part, dependent upon bacterial action, but those described above will serve as typical examples.

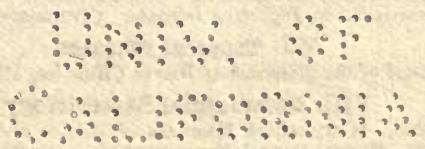




\section{BOOKS RECOMMENDED FOR A FURTHER STUDY OF THE SUBJECT}

\section{General Bacteriology and Classification}

Frost and M'Campbell. Textbook of General Bacteriology. New York, 1911. Woodhead. Bacteria and their Products. Iondon, 1891.

II. Textbooks dealing especially with Medical Bacteriology

Hewlett. Manual of Bacteriology, 4th edition. Iondon, 1911.

Jordan. A Textbook of General Bacteriology, 3rd edition. Philadelphia and Iondon, 1912.

Muir and Ritchie. Manual of Bacteriology, 6th edition. Iondon, 1913.

\section{Textbooks dealing with Pathology}

Beattie and Dickson. Textbooks of General and Special Pathology. 1908-9.

IV. Books dealing with Technique of Practical Bacteriology

Abel (translated by Gordon). Laboratory Handbook of Bacteriology, 2nd ed. 1912. Besson. Practical Bacteriology, Microbiology and Serum Therapy. (Translated by Hutchens.) 1913.

Emery. Clinical Bacteriology and Haematology, 4th edition. 1912.

Eyre. The Elements of Bacteriological Technique. A Laboratory Guide, 2nd edition. London, 1913.

\section{Public Health and Preventive Medicine}

Andrewes. Lessons in Disinfection and Sterilisation. London, 1907.

Graham-Smith. Flies in Relation to Disease (Non-Bloodsucking Flies). (Cambridge Public Health Series.) 1913.

Hewitt. House-Flies and how they spread Disease. (Cambridge Manuals of Science and Literature.) 1912.

Hindle. Flies in Relation to Disease (Biting Flies). (Cambridge Public Health Series.)

Ledingham and Arkwright. Carrier Problem in Infectious Disease. London, 1912.

Prescott and Winslow. Elements of Water Bacteriology, 3rd edition. New York, 1913.

Savage. Milk and the Public Health. Iondon, 1912.

\section{Immunity and Serology}

Allen. Vaccine Therapy: Its Theory and Practice, 4th edition. Iondon, 1912. Fraser (Elizabeth T.). A Manual of Immunity. Glasgow, 1912.

Hewlett. Serum Therapy, 2nd edition. Iondon, 1910.

Metchnikoff. Immunitys in. Infective Disegse. (Translated by Binnie.) 1905.

\section{vil. Tropiéal Diséases}

Manson. A Manual of the Diseases of Warm Climates, 4th edition. 1913.

$$
\therefore \text { VIII. Cómírercial Bacteriolog's }
$$

Chapman. Brevixg. ' (Cambridge Manufals of Science and Literature.) 1912.

Green. The Soluble Ferments and Fermentation. (Cambridge Natural Science Manuals.) 1899.

Harden. Alcoholic Fermentation. (Biochemistry Monographs.) Iondon, 1911. Marshail. Microbiology for Agricultural and Domestic Students. 1913.

Schneider. Pharmaceutical Bacteriology. Philadelphia, 1912.

IX. Other Volumes of this Series which touch upon matters dealt with in this volume

3. Biology : The Science of Life. Henderson.

4. Zoology: The Study of Animal Life. MacBride.

5. Botany : The Modern Study of Plants. Stopes.

16. The Science of Light. Phillips.

20. Youth and Sex. (Care of the Teeth, etc.) Scharlieb and Sibley.

65. Pond Life. Ash.

97. The Care of the Teeth. Young. 



$$
11
$$


$\therefore$

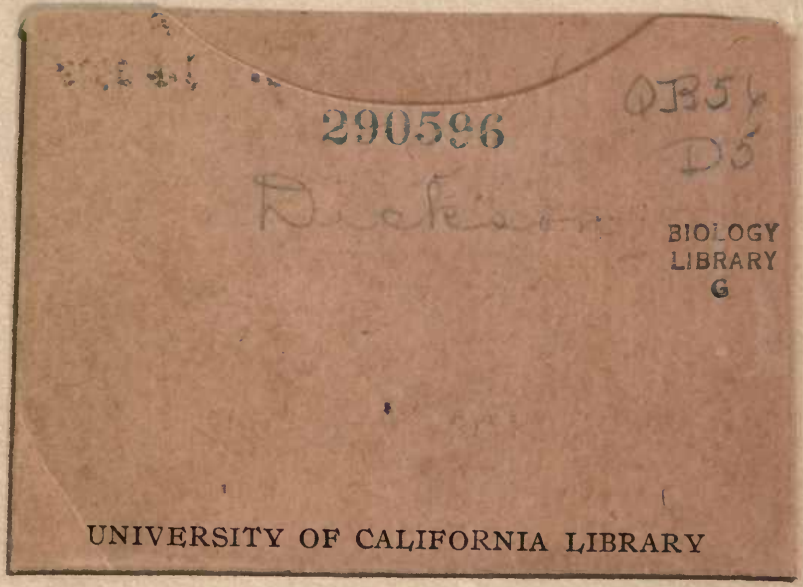


